\title{
A review of biomass burning emissions part II: intensive physical properties of biomass burning particles
}

\author{
J. S. Reid ${ }^{1}$, R. Koppmann ${ }^{2}$, T. F. Eck ${ }^{3}$, and D. P. Eleuterio ${ }^{4}$ \\ ${ }^{1}$ Marine Meteorology Division, Naval Research Laboratory, Monterey, CA, USA \\ ${ }^{2}$ Institut fuer Chemie und Dynamik der Geosphaere: Institut II: Troposphaere, Forschungszentrum Juelich, Germany \\ ${ }^{3}$ GEST Center, University of Maryland, Baltimore County, MD, USA \\ ${ }^{4}$ Dept. of Meteorology, Naval Postgraduate School, Monterey, CA, USA
}

Received: 19 April 2004 - Published in Atmos. Chem. Phys. Discuss.: 8 September 2004

Revised: 24 February 2005 - Accepted: 1 March 2005 - Published: 14 March 2005

\begin{abstract}
The last decade has seen tremendous advances in atmospheric aerosol particle research that is often performed in the context of climate and global change science. Biomass burning, one of the largest sources of accumulation mode particles globally, has been closely studied for its radiative, geochemical, and dynamic impacts. These studies have taken many forms including laboratory burns, in situ experiments, remote sensing, and modeling. While the differing perspectives of these studies have ultimately improved our qualitative understanding of biomass-burning issues, the varied nature of the work make inter-comparisons and resolutions of some specific issues difficult. In short, the literature base has become a milieu of small pieces of the biomass-burning puzzle. This manuscript, the second part of four, examines the properties of biomass-burning particle emissions. Here we review and discuss the literature concerning the measurement of smoke particle size, chemistry, thermodynamic properties, and emission factors. Where appropriate, critiques of measurement techniques are presented. We show that very large differences in measured particle properties have appeared in the literature, in particular with regards to particle carbon budgets. We investigate emissions uncertainties using scale analyses, which shows that while emission factors for grass and brush are relatively well known, very large uncertainties still exist in emission factors of boreal, temperate and some tropical forests. Based on an uncertainty analysis of the community data set of biomass burning measurements, we present simplified models for particle size and emission factors. We close this review paper with a discussion of the community experimental data, point to lapses in the data set, and prioritize future research topics.
\end{abstract}

\section{Introduction}

To understand the effects of biomass burning on the atmosphere, it is imperative that consistent parameterizations with reliable uncertainties be provided to models. In the last decade, biomass-burning studies have spawned hundreds of manuscripts on the physical, chemical, and thermodynamic properties of biomass-burning particles. Qualitatively, smoke particle properties are well understood. For example, approximately $80-90 \%$ of their volume is in the accumulation mode $\left(d_{p}<1 \mu \mathrm{m}\right)$. Smoke particles are composed of $\sim 50-60 \%$ organic carbon and $\sim 5-10 \%$ black carbon. Biomass smoke particles effectively scatter and absorb solar radiation. Given sufficient updraft velocity, smoke particles are good cloud condensation nuclei. But despite this qualitative understanding, the determination of key parameters for estimating atmospheric effects of biomass burning is not straightforward. Smoke properties vary between fires depending on fuel type and moisture, combustion phase, wind conditions, and several other variables. Also, as the physical, chemical, and optical properties of biomass-burning aerosols can change rapidly as they disperse, it is difficult to relate the properties of individual fires to the ensemble smoky hazes that affect the atmosphere's radiative balance. Determining the impacts of these hazes on the meteorology of a region is hampered by high uncertainty in both the measurement methodologies and in the models themselves. A key issue is the extent to which measurements presented in the literature can be applied to models of aged smoke that dominates regional hazes and affects seasonal climate. Ignoring the intricacies of this problem can result in very large errors in regional and global climate models.

Correspondence to: J. S. Reid

(reidj@nrlmry.navy.mil)

(C) 2005 Author(s). This work is licensed under a Creative Commons License. 
This review paper is the second of four discussing biomass-burning emissions and their physical, chemical and optical properties. The intent of this series is to present to the scientific community the state of the field, and the true uncertainties in open biomass burning (e.g., excluding cooking, charcoal production, or industrial emissions). In this manuscript we review the literature regarding intensive physical properties and emission factors and of biomass-burning particles. By intensive we mean those that describe the inherent properties of the aerosol particles themselves, such as size or chemical mass fraction, rather than extensive properties such as concentrations or total mass flux. We explore differences in particle properties by region and fire chemistry, and attempt to reconcile differences that exist between measurement techniques and field studies. In conclusion, we present what we feel are reasonable smoke models with reliable uncertainties, and make suggestions for future research.

\section{Fundamentals of particle formation}

There have been several review manuscripts and book chapters outlining the chemistry of biomass-burning combustion (for example, Tillman, 1981; Chandler et al., 1983, Pyne, 1984; Ward, 1990; Lobert and Warnatz, 1996; Simoneit, 2002). Similarly, a discussion of fire chemistry is also given in the companion paper to this manuscript (Koppmann et al., $2005^{1}$ ). Here we give only a brief description of the general properties of combustion, concentrating instead on processes related to particle formation.

It is well demonstrated that independent of fuel type, approximately $90 \%$ of the carbon released during biomass burning is oxidized to $\mathrm{CO}_{2}$ or $\mathrm{CO}$, with typically less than $5 \%$ of the carbon being released as particulate matter (e.g., Radke et al., 1991; Ward et al., 1992; Ferek et al., 1998; Andreae et al., 1998). Fires can produce both "solid" and more "liquid" aerosol particles. The particle formation process in flames begins with the creation of condensation nuclei such as polycyclic aromatic hydrocarbons (PAH) from ejected fuel gases (Glassman, 1977, 1988; Frenklach, 2002) as well as from a variety "soot-like" species (Turns, 1996). The formation of cyclic molecules and PAHs as nuclei in the flame zone is linked to the availability of double and triple bonded hydrocarbons in the fuel, and is rate limited by the formation of the first aromatic ring (Frenklach, 2002). This follows with Kent (1986) who found that soot yields from alkanes are only about half those from their alkene and alkyne (double and triple bonded carbon) counterparts, and one-third those from aliphatic-aromatics. As the PAH molecules grow to between 3000 to 10000 atomic mass units through chemical and coagulative processes, these micro-particles become

\footnotetext{
${ }^{1}$ Koppmann, R., von Czapiewski, K., and Reid, J. S.: A review of biomass burning emissions part I: Gaseous emissions and chemistry, Atmos. Chem. Phys. Discuss., in preparation, 2005.
}

condensation nuclei for other pyrolized species, and may experience considerable growth. Subsequently, many of these particles may in turn be reduced in size through further oxidation in the interior of the flame zone if temperatures exceed $1100 \mathrm{~K}$ (Glassman, 1977). If insufficient oxygen is transported into the flame (extreme oxygen deprived pyrolysis such as in the interior of very large fires), or if the temperature is not high enough to complete oxidation $(\mathrm{T}<1100 \mathrm{~K})$, many of these particles may undergo a secondary condensation growth phase and be emitted in the form of smoke.

The specific relationships in real fires between fuel variability, burning environment, and flaming phase particle production are complicated, and defy simple parameterization. However there are a few macroscopic generalities that match the above theory of particle production. Laboratory studies suggest that the rate of particle production during flaming combustion is power law proportional to flame size (Glassman, 1977, 1988) and inversely proportional to the oxygen content of the fuel (Ward, 1980). Increased fire intensity (as in area and crown fires) reduces oxygen transport into the interior flame zone and has been shown to increase particle size and production (Ward, 1990; Cofer et al., 1996; Reid and Hobbs, 1998).

Smoldering combustion begins when most of the volatiles have been expelled from the cellulose fuel (Chandler et al., 1983). In essence, smoldering combustion is a surface process. Oxygen diffuses to the surface and reacts exothermally with carbon at temperatures $>710 \mathrm{~K}$. If temperatures are increased to $910-980 \mathrm{~K}, \mathrm{CO}$ can convert to $\mathrm{CO}_{2}$. Because PAHs tend to form at higher temperatures, the mass fraction of soot in smoke particles that is produced in smoldering combustion is extremely low, and particle formation may occur around other nuclei. There have been few studies of aerosol formation in the smoldering phase, but it is known that the particles are largely formed by the condensation of volatilized organics on any available particles or surfaces (Ward, 1990).

The above description of particle formation fits with wellknown fundamentals of biomass burning. The underlying theme is that particle formation during biomass burning is essentially a condensation process. Consequently, the overwhelming majority of particle mass is in the accumulation mode (Radke et al., 1991; Liousse et al., 1995; Hobbs et al., 1996; Reid and Hobbs, 1998). Particles formed under lower temperature smoldering and ignition phases are probably condensation nuclei limited, but can produce larger particles due to the presence of more un-combusted condensate. Large intense fires that have very high temperatures and are oxygen limited produce larger soot-based particles with more of non-spherical chain-like structure (Martins et al., 1998b; Reid and Hobbs, 1998). 


\section{Size and morphology of freshly generated smoke par- ticles}

Smoke particle number and mass are overwhelmingly in the accumulation mode. Scanning and transmission electron microscopy studies have shown smoke particles to have a variety of morphologies such as chain aggregates, solid irregulars and more liquid/spherical shapes (for example, see Cachier, et al., 1991; Woods et al., 1991; Gaudichet et al., 1995; Martins et al., 1996, 1998b; Reid and Hobbs, 1998; Ruellan et al., 1999; Posfai et al., 2003). An example of smoke particles collected in Brazil is presented in Fig. 1. As black carbon chain aggregates produced in the flame zone can serve as condensation nuclei for low vapor pressure organics that survive oxidation, it is not uncommon for micrographs to show particles as semi-spherical/semi-liquid droplets with solid complex cores. There is a trend towards more complicated shapes at higher combustion efficiencies and temperatures (Martins et al., 1996; Posfai et al., 2003). Solid cores typically account for one third to two thirds of the total particle diameter, or 4-30\% of the volume (Reid and Hobbs, 1998). In extreme oxidation environments with high combustion efficiencies, uncoated chain aggregates are emitted (e.g., Cachier et al., 1991; Woods et al., 1991; and Posfai et al., 2003). Conversely, spherical particles without observable nuclei (termed "tar-balls", Posfai et al., 2003) are more often associated with smoldering combustion. However, ill defined semi-volatile organic compounds (SVOCwhich can be a significant fraction of particle mass - Eatough et al., 2003) cannot be seen by electron microscopy since they volatilize under the extreme vacuum and energies of the microscope. Other less volatile layers will outgas under these conditions, leaving a visible ring around the particle in the microscope images.

While lower in mass fraction than accumulation mode particles $(\sim 10 \%)$, fires produce a variety of coarse mode particles (typically $2.5-15 \mu \mathrm{m}$ diameter). In addition to coarse mode ash particles $\left(2<d_{p}<20 \mu \mathrm{m}\right)$, giant ash particles having diameters of up to a millimeter or more can be generated by very intense fires (these have even been tracked by weather radar). Ash falls of these giant particles are commonly reported more than fifty kilometers from the source. In addition, small non-combustible matter on or around foliage in the fire zone is often entrained into fire plumes. This entrainment has been attributed to the high surface winds associated with the convective updraft (Palmer et al., 1981; Maenhaut et al., 1996), with significant amounts of dirt mixed in with slash piles during logging operations (Ward and Hardy, 1991; Ward, personal communication), and with soil particles being suspended by saltation of surface dust driven by fire generated winds (Radke et al., 1991). Because the coarse mode consists of ash, carbon aggregates, partially combusted foliage, and soil particles, shapes are generally quite complicated (Radke et al., 1991; Martins et al., 1996; Reid and Hobbs, 1998). Consequently, the difference be-

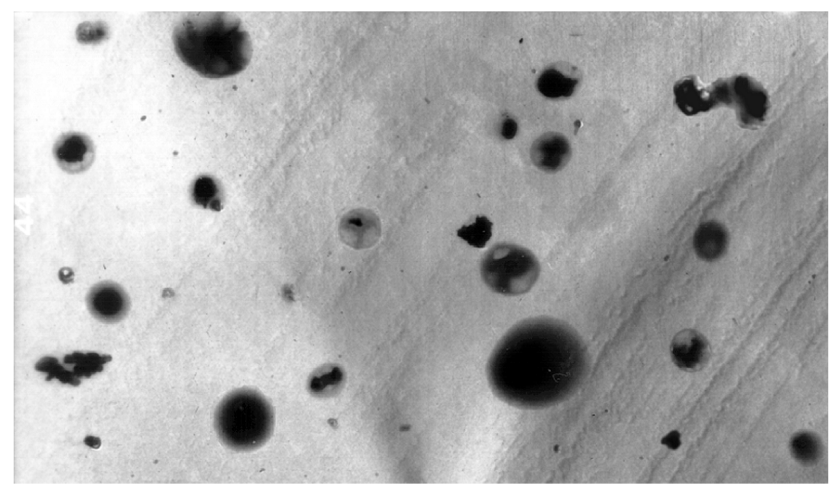

Fig. 1. Transmission electron micrograph of accumulation mode smoke particles collected in a smoke dominated regional haze in Brazil.

tween geometric, equivalent mass, and aerodynamic diameters can vary by more than a factor of 2 , and the relationship between the geometric and equivalent optical diameters for such ash aggregates is even more uncertain (Reid et al., 1994). Thus, even though such particles may only account for $\sim 10-20 \%$ of the measured particle mass, their contributions to absorption and scattering properties of the aerosol are uncertain and probably cannot always be neglected.

Table 1 summarizes reported accumulation mode particle size distribution parameters for fresh smoke samples. While combustion can be divided into flaming and smoldering processes, plumes measured in the field are made up of particles from both, and are technically "mixed phase". In this table we separate plumes by their modified combustion efficiency $\left(\mathrm{CO}_{2} /\left(\mathrm{CO}+\mathrm{CO}_{2}\right)\right)$ at greater than or less than 0.9 to determine dominance of flaming or smoldering combustion, respectively, knowing that true differentiation is less than distinct.

Sizing of smoke particles is performed from a variety of techniques based on particle optical, aerodynamic, equivalent mobility, and geometric size. Most reports give similar results, with aerosol count median diameters (CMDs) for fresh smoke in the $0.10-0.16 \mu \mathrm{m}$ range, centered at $\sim 0.13 \mu \mathrm{m}$. Volume median diameters are also consistent with typical values in the $0.25-0.3 \mu \mathrm{m}$ range (but with some reported values as high as $0.5 \mu \mathrm{m}$ ). Geometric standard deviations for both the number and volume distributions are on the order of 1.5-1.9, with a reasonable mean value of $\sim 1.7-1.8$. Recent studies of smoke properties using inversion techniques in historically data void regions of the world have observed or inferred the presence of very large smokehaze particles from peat fires (Nakajima et al., 1999; Eck et al., 2003). In these cases the VMD has been found to be as large as $0.5 \mu \mathrm{m}$ in aged smoke. While this may be in part due to aging processes (see Sect. 6), it has been suggested that smoldering peat fires can produce particles substantially larger and more hygroscopic than most other fuels. 
Table 1. Accumulation mode dry particle size distribution parameters for fresh smoke. DMPS=Differential Mobility Particle Sizer. IMP=Cascade Impactor. OPC=Optical particle counter. SEM=Scanning electron microscopy. Phase F=Flaming, S=Smoldering, M=Mixed . $\mathrm{CMD}=$ count median diameter. $\sigma_{g c}=$ geometric standard deviation of number distribution. $\mathrm{VMD}=$ Volume median diameter. $\sigma_{g v}=$ geometric standard deviation of volume distribution.

\begin{tabular}{|c|c|c|c|c|c|c|c|c|}
\hline & Method & Notes & Phase & \# & CMD & $\sigma_{g c}$ & VMD & $\sigma_{g v}$ \\
\hline \multicolumn{9}{|l|}{ Grass/Savanna/Cerrado } \\
\hline LeCanut et al. (1996) & OPC & Savanna & $\mathrm{F}$ & 25 & $0.125 \pm 0.02$ & & $0.25 \pm 0.02$ & \\
\hline Reid and Hobbs (1998) & DMPS & Grass & $\mathrm{F}$ & 6 & $0.10 \pm 0.01$ & $1.79 \pm 0.05$ & $0.30 \pm 0.04$ & $1.87 \pm 0.07$ \\
\hline Reid and Hobbs (1998) & DMPS & Cerrado & $\mathrm{F}$ & 6 & $0.10 \pm 0.01$ & $1.91 \pm 0.15$ & $0.23 \pm 0.02$ & $1.80 \pm 0.14$ \\
\hline \multicolumn{9}{|l|}{ Temperate } \\
\hline Einfeld et al. (1991) & OPC & Prescribed & $\mathrm{F}$ & 1 & $0.12 *$ & & 0.21 & 1.9 \\
\hline Hobbs et al. (1996) & DMPS & Prescribed & $\mathrm{F}$ & 3 & $0.16 \pm 0.02$ & $1.55 \pm 0.1$ & $0.25 \pm 0.02$ & $1.6 \pm 0.1$ \\
\hline Reid (1998) & DMPS & Wildfire & M & 1 & 0.13 & 1.5 & 0.25 & 1.6 \\
\hline Martins et al. (1996) & SEM & Prescribed & $\mathrm{F}$ & 3 & 0.14 & 1.65 & $\sim 0.29 *$ & \\
\hline Stith et al. (1981) & OPC & Prescribed & $\mathrm{F}$ & 3 & $\sim 0.13$ & & $\sim 0.3$ & \\
\hline Einfeld et al. (1991) & OPC & Prescribed & $\mathrm{S}$ & 1 & $0.18 *$ & & 0.25 & 2.5 \\
\hline Hobbs et al. (1996) & DMPS & Prescribed & $\mathrm{S}$ & 1 & 0.12 & 1.50 & 0.24 & 1.68 \\
\hline Martins et al. (1996) & SEM & Prescribed. & $\mathrm{S}$ & 1 & 0.18 & 1.45 & $\sim 0.27 *$ & \\
\hline \multicolumn{9}{|l|}{ Tropical Forest } \\
\hline Reid and Hobbs (1998) & DMPS & Deforestation/slash & $\mathrm{F}$ & 6 & $0.13 \pm 0.01$ & $1.68 \pm 0.02$ & $0.24 \pm 0.01$ & $1.62 \pm 0.07$ \\
\hline Reid and Hobbs (1998) & DMPS & Deforestation/slash & $\mathrm{S}$ & 6 & $0.10 \pm 0.01$ & $1.77 \pm 0.02$ & $0.29 \pm 0.01$ & $1.84 \pm 0.05$ \\
\hline \multicolumn{9}{|l|}{ Other } \\
\hline Jenkins et al. (1991) & IMP & Rice Straw & $\mathrm{F}$ & 2 & & & 0.47 & 1.63 \\
\hline Woods et al. (1991) & SEM & Wetlands & $\mathrm{F}$ & 1 & 0.2 & & & \\
\hline Woods et al. (1991) & SEM & Wetlands & $\mathrm{S}$ & 1 & 0.3 & & & \\
\hline
\end{tabular}

* Estimated from Hatch-Choat equations.

Instrumentation error can be severe when measuring high concentration smoke plumes. There are some systematic differences in Table 1 based on technique. For example, the most significant outlier was reported by Jenkins et al. (1991); based on cascade impactor samples that may be biased since they had poor resolution in the sub-micron range, or by the specific conditions in their combustion wind tunnel. Electron microscope particle size reports tend to be larger than optical particle counter and differential mobility measurements as particles flatten on impact with the collection substrate. Further, in some collection methods, such as impactors, there is a natural bias towards larger particles. However, most measurements are based on optical particle counters that must be for corrected for particle index of refraction. For smoke plumes (where typical particle concentrations are typically $>20000 \mathrm{~cm}^{-3}$ ), coincidence errors introduce the highest uncertainty. While many previous studies made successful use of the Active Scattering Aerosol Spectrometer probe (ASASP), the Passive Cavity Aerosol Spectrometer Probe (PCASP) introduces errors at concentrations as low as $8000 \mathrm{~cm}^{-3}$ and may become uncorrectable at $20000 \mathrm{~cm}^{-3}$ (Reid, 1998). If available and properly employed, differential mobility analyzer (DMA) data is probably of the most value. Becuase smoke plumes have high particle concentrations, the new generation of very rapid scanning DMA sys- tems hold significant promise if proper inversion techniques are used (e.g., Collins et al., 2002).

Despite relatively few measurements in the literature, reports on differences in size relating to combustion efficiency are also available. Studies that presented particle size measurements for both the flaming and smoldering phases of a moderately sized fire have tended to show larger particle sizes for lower combustion efficiency (e.g., Einfeld et al., 1991; Woods et al., 1991; Martins et al., 1996; Reid and Hobbs, 1998). This is consistent with the physics of smoldering/mixed phase combustion, where a lower fraction of the fuel gas is oxidized in the flame zone, leaving it free to condense on available $\mathrm{CN}$. These particles are subsequently emitted with short or no exposure to the flame zone, resulting in a larger average size. However, other studies have shown the situation is more complex since higher concentrations of incomplete combustion products are formed in very intense fires (Cofer et al., 1989, 1996). The largest prescribed fire reported in Hobbs et al. (1996) exhibited larger particles during flaming phase combustion than during the smoldering phase. The fires reported in Hobbs et al. (1996) were extremely intense prescribed burns. In such burns, it is likely that, while there is very high heat and combustion rates, extensive oxygen deprivation occurs in the interior flame zone (e.g., entrainment limited) preventing fuel oxidation (Palmer et al., 
1981), and resulting in particles that are more irregular (e.g., Martins et al., 1996; Posfai et al., 2003). Further, the very high particle concentrations and temperatures in large fires accelerate the coagulation process above the flame-zone, resulting in even larger particles. Reid and Hobbs (1998) showed even more complicated behavior for forest fires in Brazil, and suggested that fire intensity may be as important as combustion efficiency in determining fresh particle size during emission. This complexity is consistent with the understanding that while flaming and smoldering combustion both contain condensation processes, they are subjected to widely differing environments.

Intensity considerations also explain some differences in particle size found between different fuel types. Table 1 indicates that smoke particles from studies on North American forest fires may be larger than those produced in other parts of the world (on the order of 10-30\%). This difference may be due to the fact that the temperate fires studied in North America (Radke et al., 1991; Einfeld, 1991; Hobbs et al., 1996) tended to be larger and more intense than the smaller prescribed burning fires of South America (Reid and Hobbs, 1998). However, since there are so few published measurements on source size distributions, whether this difference is representative of the fuel types as a whole at this point is probably only bordering on statistical significance.

Reported values of particle density based on simultaneous mass and size distribution measurements vary widely, with Stith et al. (1981) deriving values between 0.79 and $1.35 \mathrm{~g} \mathrm{~cm}^{-3}$ for smoke from two temperate fires, Radke et al. (1988, 1991) and Martins et al. (1996) respectively estimating mean values of $1 \mathrm{~g} \mathrm{~cm}^{-3}$ and $1.53 \mathrm{~g} \mathrm{~cm}^{-3}$ for temperate forest fires, and Reid and Hobbs (1998) deriving a mean value of $1.35 \mathrm{~g} \mathrm{~cm}^{-3}$ for fires in the Amazon basin. This difference can in part be linked to measurement methods, with both Stith et al. (1981) and Radke et al. (1988, 1991) utilizing optical particle counters that are sensitive to index of refraction corrections. Recently, Turpin and Lim (2001) suggested that an average value for organic species in the atmosphere (including species common in smoke) is $\sim 1.2 \mathrm{~g} \mathrm{~cm}^{-3}$. Given that $15 \%$ of fresh smoke particle mass is either black carbon on trace inorganic species (as discussed in the next section), and that this refractive material has density around $1.8-2.2 \mathrm{~g} \mathrm{~cm}^{-3}$, the average density of dry smoke particles likely varies in the $1.20-1.4 \mathrm{~g} \mathrm{~cm}^{-3}$ range.

\section{Particle chemistry}

Accumulation mode particles generated by biomass burning have been shown to have three principal components: Particulate organic material (POM carbon with the associated organic matter such as $\mathrm{H}, \mathrm{N}$, and $\mathrm{O}$ ), black carbon (i.e., soot), and trace inorganic species. Reported data indicates that on average POM accounts for $\sim 80 \%$ of the mass of fresh dry smoke particles, followed by $\sim 5-9 \%$ for black carbon, and $\sim 12-15 \%$ for other trace inorganic species

Organic material can be described as those molecules consisting of chained carbon atoms along with hydrogen and other various elements and functional groups. By extended definition, organic carbon (OC) is simply the carbon in these organic compounds. In contrast, there is no standard definition for black carbon (BC). Novakov et al. (1982) defines black carbon as a highly light absorbing carbon based material, such as soot, that has a graphitic-like structure. Black carbon is highly absorbing compared to other aerosol species, and therefore often assumed to be responsible for all short-wave radiation absorption in polluted air. Often this material is referred to as "elemental" or "graphitic" carbon, though this nomenclature is technically incorrect. There are in fact a variety of "soot-like" species that absorb light to varying degrees (Liousse et al., 1993). Like organic carbon, black carbon can have associated hydrogen, oxygen, and nitrogen atoms, although in much smaller percentages.

\subsection{Compositional analysis methods}

A thorough discussion of smoke particle chemistry requires a review of the true uncertainty of reported data, and knowledge of how particle composition is quantified. What must be clearly understood is that the quantification of the two largest components of biomass burning particles (organic and black carbon) has been founded on indirect assumptions rather than on any quantitative chemical formulation. In general, these indirect measurement techniques are either based on the thermal combustion or the light absorption properties of the material.

The total amount of smoke particle carbon collected on filter samples is routinely measured using various Thermal Evolution (TE)/Evolved Gas Analysis (EGA) based techniques. Collected smoke particles on a quartz filters are heated in steps to temperatures to over $800^{\circ} \mathrm{C}$, and oxidized. Eventually, (sometimes through the use of a catalyst) nearly all of the carbon in the sample is oxidized to measurable $\mathrm{CO}_{2}$. Several studies have shown that most commonly used TE based techniques can measure the total amount of carbon on a quartz filter to within $10 \%$ (e.g., Shah and Rau, 1991; Schmidt, et al., 2001).

While the total amount of carbon on an aerosol sample can be well known, significant uncertainties arise in TE/EGA methods when investigators differentiate between organic carbon and black carbon by exploiting their respective thermal behavior. Most organic carbon compounds evolve off of filters at temperatures $<500^{\circ} \mathrm{C}$, whereas black carbon-like compounds evolve at temperatures up to $1200^{\circ} \mathrm{C}$ (Novakov, 1982). In these TE/EGA methods, a thermal pretreatment is performed on the quartz filter sample at a series of temperature steps to remove organic matter. This organic matter is oxidized to $\mathrm{CO}_{2}$ for subsequent measurement to determine the amount of organic carbon evolved at each temperature 
step. The filter sample is then exposed to higher temperatures (and in some cases oxygen concentrations) in steps to evolve and oxidize the remaining carbon on the filter (presumed to be $\mathrm{BC}$ and soil carbonates). The end result is a thermogram of evolved carbon as a function of temperature. Functionally, these methods suffer from significant shortcomings, not the least of which is the assumption that species that evolve at higher temperatures $\left(>500^{\circ} \mathrm{C}\right)$ are solely black carbon. Mayol-Bracero et al. (2002) suggests that much of what is assumed to be $\mathrm{BC}$ may in fact be organic species.

There are many thermal methods in use, each with unique procedural modifications such as pretreatment and oxidation methods (e.g., Cadle et al., 1980; Novakov, 1982; Tanner et al., 1982; Ohta and Okita, 1984; Cachier et al., 1989). Intercomparison studies have shown that if the aerosol has a high organic carbon content (such as biomass-burning aerosols), even minor procedural differences can result in $>50 \%$ differences in the derived value of the ratio of BC to OC (Shah and Rau, 1991). Strict attention must be paid to operational definitions of the temperatures at which "organic" and "black" carbon evolve because corrections are necessary to account for chemical reactions that take place during analysis (Chow et al., 2001). Other uncertainties include the pyrolysis of organic matter (charring) and its conversion into BC (Tanner et al., 1982; Cadle et al., 1983), and conversely, the premature evolution of $\mathrm{BC}$ at lower than expected temperatures. The presence of alkali earth compounds such as potassium (which is found in smoke particles) has been theorized to cause premature evolution of BC (Novakov and Corrigan, 1995, 1996b).

Aside from these procedural differences, the low reproducibility in samples analyzed from various TE techniques is due in part to the inherent vulnerability to artifacts when sampling carbonaceous particles (e.g., Appel et al., 1983, 1989). Note that thus far we have only discussed the analysis of carbon on filters, which is not necessarily the amount of particulate carbon in the atmosphere. Artifacts can be positive or negative, as the quartz filters can adsorb semi-volatile organic species (SVOC), and particles can out-gas (McDow and Huntzicker, 1990). To partially account for these artifacts, up to four filters or denuders in series or in parallel are sometimes used (Novakov et al., 1997; Turpin et al., 2000; Lewtas et al., 2001). The end result of these corrections is a more accurate estimate of the $\mathrm{OC}$ to $\mathrm{BC}$ partition in the sample. However, these precautions have been applied inconsistently in the literature.

The summation of all of these variances in the TE methods leads inevitably to the realization that results must be treated as semi-quantitative, and the best an investigator can currently hope for is consistency. Thermograms can be assessed individually, thus reducing the uncertainty (e.g., Novakov et al., 1997), but since no single laboratory or investigator accounts for all of these biases in the same way, the $50 \%$ difference in laboratory comparisons of BC:OC ratios from a decade ago still exist today (Schmidt et al., 2001).
Another frequently employed method to determine the concentration of black carbon in aerosol particle samples uses optical absorption techniques. These methods base their estimation of the black carbon concentration on the transmission or reflection of light off a filter sample. Once the transmission or reflectance measurement is made, these methods simply apply a specific absorption factor for black carbon to convert absorption into a BC concentration. Continuous reading instruments such as the ThermoAndersen Inc. Aethalometer, and the Radiance Research Inc. Particle Soot Absorption Photometer (PSAP) are frequently employed and used to infer a BC concentration. These optical techniques are also frequently applied to individual filter samples (e.g., Lin et al., 1973; Delumea et al., 1980; Campbell et al., 1996; Martins et al., 1996; Martins et al., 1998a). As is discussed in the companion papers to this manuscript (such as Reid et al., 2004), the specific absorption of black carbon (that is to say the absorption cross section for a given amount of black carbon mass) is highly variable. Thus, while this method is simple, relatively inexpensive, and can be applied consistently, it has absolute errors for BC of greater magnitude than the thermal techniques (Reid et al., 1998a) and we do not include them in our evaluation of BC.

In an attempt to better quantify ambiguous organic carbon measurements, there have been studies of organic carbon speciation. Such speciation requires using ion chromatography (IC), high performance liquid chromatography (HPLC), and gas chromatography/mass spectroscopy techniques (see Finlayson-Pitts and Pitts, 1986 for a description). Organic acids, are easily extractable and are commonly reported in biomass burning studies using IC/HPLC techniques (e.g., Andreae et al., 1988; Helas et al., 1992; Andreae et al., 1998; Reid et al., 1998b; Ruellan et al., 1999; Mayol-Bracero et al., 2000, 2002; Yamasoe et al., 2000; Gao et al., 2003a).

Gas Chromatography/Mass Spectroscopy (GC/MS) has also been used to speciate the organic component of smoke particles (e.g., Mazurek et al., 1991; McKenzie et al., 1994; Radzi bin Abas et al., 1995; Elias et al., 1999; Silva et al., 1999; Mayol-Bracero et al., 2000). These methods can quantify alcohol, sugar, and a variety of organic acid species on both filter samples and individual particles. When performed on particles collected on filters, such organic analysis requires sample extraction with water or other solvents such as dichloro-methane. Between extraction and peak identification issues, only $\sim 5$ to $20 \%$ of organic carbon from smoke can be speciated. Because these methods are so labor intensive, only a very few samples are ever subjected to this analysis.

Unlike the organic components of smoke, inorganic trace elements of smoke particles are frequently and accurately determined. Trace element and some organic compound speciation is commonly performed using IC and X-ray techniques (for example Proton Induced X-ray Emission-PIXE, X-ray florescence-XRF, and Energy Dispersive Analysis with XRays-EDAX). Intercomparison studies between soluble ions 
and X-ray methods for biomass burning particles show good agreement, with IC extraction efficiencies for the species above of better than $80 \%$ (Calloway et al., 1989; Turn et al., 1997; Reid et al., 1998b; Yamasoe et al., 2000).

\subsection{Particle composition}

A summary of studies presenting carbon apportionment from TE/EGA based techniques is given in Table 2. Findings from studies presenting key trace elements are presented in $\mathrm{Ta}-$ ble 3. Reports suggest that carbon accounts for $\sim 50$ to $70 \%$ of the mass of all particle emissions, with $\sim 55 \%$ and $\sim 8 \%$ of fine particle mass is classified as organic and black carbon, respectively. Approximately $10 \%$ of fine-mode mass of fresh smoke is composed of trace inorganic species, most notably potassium, chlorine, and calcium, that are likely present in the particle core. This leaves approximately 20-30\% of fine particle mass as elements associated with the organic and black carbon compounds such as hydrogen, oxygen, and nitrogen (or a TOM/OC ratio of $\sim 1.5$ ).

Given the wide variations in the emission factors of particle mass by fuel type and combustion efficiency (as will be discussed later), and the large uncertainties inherent in thermal analytical techniques, the reported mass fractions of organic carbon in smoke aerosol particles are variable. For example, in all flaming fires, the organic content of the emitted aerosols was $53 \pm 8 \%$ (range of $\sim 37-65 \%$ ). For smoldering phase combustion, organic carbon reports are higher, at $62 \pm 6 \%$ of mass. This increase in the average mass fraction of organic carbon with smoldering combustion is logical as this process occurs after most of the fuel solids are expelled and a lower temperatures without flame pyrolysis where the combustion of organic matter can take place (Ward et al., 1990). Much of the variance in these values could be due to fire variability. Indeed, there are relatively few measurements. Examination of Table 2 also shows that the standard deviation of values for each individual study is large. Thus, while some of this variance may be due to true natural variability, we cannot exclude the large uncertainties associated with the thermal methods.

The black carbon content of biomass burning particles has even more variability and uncertainty than organic carbon. Typically, the black carbon/organic carbon ratio is in the $1: 8$ to $1: 12$ range. From Table 2 the mean black carbon mass fraction reported in the literature was $8 \% \pm 6$, and ranged from 2-27\%. As expected, some of this variance is attributable to combustion phase, with black carbon concentrations for smoldering phase combustion being a relatively consistent $\sim 2-5 \%$. In contrast, the black carbon content during flaming phase combustion is higher and varies by over a factor of 5. While it is known that the analysis of black carbon suffers from numerous artifacts for which a factor of 2 uncertainty is not unreasonable, some of the variance reported can be shown to be due to natural variation. Ferek et al. (1998) and Reid and Hobbs (1998) showed that for tropi- cal forest fires, the black carbon content could vary from 2$30 \%$, depending on fire chemistry. It is known that this variance was in fact physical, as the black carbon content correlated with optical measurements of single-scattering albedo (at 30\% black carbon by mass, the single-scattering albedo dropped to $\sim 0.4-$ near the theoretical limit).

The ratio between organic carbon and particulate organic matter (POM) in smoke particles is highly uncertain. Typically, the ratio is simply estimated by the amount of undetermined mass in the sample. So, if organic carbon, black carbon and trace inorganic species make up, say, 55\%, 9\% and $9 \%$, respectively, then that implies an POM/OC ratio of $\sim 1.5$. Based on the measurements in Tables 2 and 3 , values can range from 1.4 to 1.8 . However, these values are different from what is often suggested in the literature. Turpin and Lin. (2001) found that values below 1.4 are likely unphysical and they recommend values as high as 2 for non-urban environments. Reports for smoke particles are in the middle of this range. As these reports are based on what is not measured rather than what is, and since thermal methods are prone to such large artifacts, the mean value still may not be more than an educated guess.

There has never been a full quantification of all of the molecular species making up the carbon-based components of smoke particles. Based on a combination of GC/MS, HPLC, X-ray analysis, and black carbon from thermal methods, 25-40\% can be speciated (higher speciation percentages are typically associated with aged smoke). Compounding the organic speciation difficulties is that $20-35 \%$ of smoke particle mass may be from "semi-volatile organics", ill-defined species whose presence may or may not be included in these analyses (Eatough et al., 2003). However, there has been enough research to infer and categorize the organic species based on their general chemical properties. Woody fuels consist mainly of cellulose, hemicelluloses, and lignins. Since the organic fraction of smoke particles is composed of unburned fuel components and products of incomplete combustion, the bulk of the organic fraction of wood smoke is likely to be composed of compounds structurally related to the thermally decomposed products of these wood components (McDow et al., 1996; Gao et al., 2003a). Most common are carbohydrates (predominately levoglucosan) accounting for $7-14 \%$ of fresh smoke particle mass (Fraser and Lakshmanan, 2000; Gao et al., 2003a). Levoglucosan alone can account for $5 \%$ of particle mass (Hornig et al., 1985; Graham et al., 2002). During the combustion process much of the levoglucosan pyrolizes into acetic acid, acetone, phenols, and water (Goos, 1952). Methoxyphenols have been found in similar concentrations in wood smoke (Hawthorne et al., 1989). Aldehydes (such as furfuraldehyde) are also present.

Because cellulose is water soluble, it is not unreasonable for most of the organic carbon making up smoke particles to be water-soluble. Novakov and Corrigan (1996a) showed that the smoke from smoldering pure cellulose was $99 \%$ soluble. For smoke produced by burning actual woody fuels, 
Table 2. Summary of carbon apportionment studies of fresh biomass burning particles from thermal evolution (TE) techniques. C89=Cachier et al. (1989); C93=Chow et al. (1993); J81=Johnson et al. (1981); SL=Sunset Labs Corporation commercially using the J81 technique. Phase: $\mathrm{F}=$ Flaming, $\mathrm{M}=$ mixed, $\mathrm{S}=$ Smoldering.

\begin{tabular}{|c|c|c|c|c|c|c|c|}
\hline Reference & Notes & Method & $\#$ & Phase & OC Mass Fraction (\%) & BC Mass Fraction (\%) & BC/OC Ratio \\
\hline Andreae et al. (1998) & Savanna & $\mathrm{C} 89$ & 1 & $\mathrm{~F}$ & 44 & 10 & 0.23 \\
\hline Cachier et al. (1996) & Savanna & $\mathrm{C} 89$ & 3 & $\mathrm{~F}$ & $37 \pm 4$ & $4.4 \pm 0.3$ & 0.12 \\
\hline Ferek et al. (1998) & Cerrado & $\mathrm{C} 89$ & 6 & $\mathrm{~F}$ & $61 \pm 20$ & $7.5 \pm 4.0$ & 0.12 \\
\hline Ferek et al. (1998) & Grass/Pasture & $\mathrm{C} 89$ & 6 & $\mathrm{~F}$ & $66 \pm 11$ & $7.5 \pm 3.1$ & 0.11 \\
\hline Ward et al. (1992) & Cerrado & SL & N/A & & $\sim 57$ & 3.3 & 0.06 \\
\hline \multicolumn{8}{|l|}{ Temperate/Boreal } \\
\hline Hobbs et al. (1996) & Presc. Temperate & SL & 3 & $\mathrm{~F}$ & $46 \pm 18$ & $4 \pm 2$ & $0.08 \pm 0.02$ \\
\hline Mazurek et al. (1991) & Boreal & $\mathrm{J} 81$ & 2 & $\mathrm{~F}$ & & & $0.07 \pm 0.02$ \\
\hline Susott et al. (1991) & Temperate & SL & 1 & $\mathrm{~F}$ & 45.5 & 8.1 & 0.15 \\
\hline \multicolumn{8}{|l|}{ Tropical Forest } \\
\hline Ferek et al. (1998) & S. Amer. & $\mathrm{C} 89$ & 6 & $\mathrm{~F}$ & $53 \pm 20$ & $7.9 \pm 4.0$ & 0.15 \\
\hline Ferek et al. (1998) & S. Amer. & $\mathrm{C} 89$ & 6 & $\mathrm{~S}$ & $67 \pm 11$ & $5.3 \pm 2.0$ & 0.08 \\
\hline Ward et al. (1992) & S. Amer. & SL & N/A & $\mathrm{F}$ & $\sim 50$ & $\sim 10$ & $\sim 0.2$ \\
\hline \multicolumn{8}{|l|}{ Other } \\
\hline Patterson (1984) & Forest Debris & J81 & 3 & $\mathrm{~F}$ & $45 \pm 5$ & $27 \pm 6$ & 0.6 \\
\hline Turn et al. (1997) & Herbatious Fuel & C93 & 16 & $\mathrm{~F}$ & $31 \pm .85$ & $16 \pm 0.4$ & 0.52 \\
\hline Turn et al. (1997) & Woody Fuel & C93 & 8 & M & $46 \pm 1.8$ & $22 \pm 1$ & 0.48 \\
\hline
\end{tabular}

Novakov and Corrigan (1996a), Graham et al. (2002) and Mayol-Bracero et al. $(2000,2002)$ gave water extraction efficiencies for carbon on the order of $40-80 \%$. The bulk of these compounds cannot be directly speciated through HPLC or GC/MS techniques ( $<35 \%$ speciation combined). Of the water soluble organic component of smoke particles, just under one half are thought to be organic acids (equally partitioned between mono- and poly-acids) with the remainder being indeterminate or neutral, such as alcohols (Mazurek et al., 1991, 1996; Mayol-Bracero et al., 2000, 2002; Gao et al., 2003a; Graham et al., 2002). Commonly measured organic acids in fresh smoke particles such as formate, acetate, and oxalate, typically make up $<1 \%$ of total particle mass each (Ferek et al., 1998; Yamasoe et al., 2000). More advanced techniques have identified gluconate as the dominant acid (Gao et al., 2003a). Also present in trace quantities (on the order of $<5 \%$ of total mass) are miscellaneous alcohols and sugars.

Through GC/MS studies of filters using methylene chloride extraction, aliphatics, PAHs, esters and alkanols have also been observed (e.g., Simoneit et al., 1996; Fang et al., 1999). On a similar magnitude as the acids, straight chain $\mathrm{n}$-alkanes with carbon numbers on the order of 24-34 are prevalent. Fang et al. (1999) showed that for such species, carbon numbers on the order of 29-31 are favored. Similar studies have shown PAHs (the nuclei on which particles form) make up less than $1 \%$ of smoke particle mass (Kamens et al., 1988).

Because ion chromatography and X-ray analysis for trace inorganic species is precise and inexpensive there have been numerous data sets using these methods presented in the literature. A summary of key data sets for fresh smoke is presented in Table 3. Full X-ray analysis of samples can be found in such papers as Artaxo et al. (1994), Gaudichet et al. (1995), Maenhaut et al. (1996), and Yamasoe et al. (2000). Alkali earths and halides tend to dominate the inorganic species. Potassium and chloride each account for $2-5 \%$ of fine particle mass. It has been often suggested that they are likely in the form of potassium chloride in the core of smoke particles with black carbon (e.g., Posfai et al., 2003). Sulfur in the form of sulfate is also present at $\sim 1 \%$ of fine particle mass.

Although only a small fraction of particle mass $(\sim<10 \%)$, trace inorganic species analysis has played a significant role in the understanding biomass burning particle chemistry. Receptor models attempting to apportion the ambient pollution 
Table 3. Key particle trace element composition estimates for fresh smoke from various biome types. Units are mass percentage. $\mathrm{P}=\mathrm{Phase}$ $\mathrm{F}=$ Flaming, $\mathrm{S}=$ Smoldering, $\mathrm{M}=$ Mixed. bdl=below detectable limits.

\begin{tabular}{|c|c|c|c|c|c|c|c|c|c|c|c|}
\hline Reference & $P$ & $\mathrm{OC}$ & $\mathrm{BC}$ & $\mathrm{Na}$ & $\mathrm{Mg}$ & $\mathrm{Si}$ & $\mathrm{S}$ & $\mathrm{Cl}$ & $\mathrm{K}$ & $\mathrm{Ca}$ & $\mathrm{Fe}$ \\
\hline \multicolumn{12}{|l|}{ SA Grasslands } \\
\hline Ferek et al. (1998) & $\mathrm{F}$ & $66 \pm 11$ & $7.5 \pm 3.1$ & $0.1 \pm 0.3$ & $0.3 \pm 0.3$ & N/A & $0.6 \pm 0.3$ & $1.7 \pm 1.0$ & $2.9 \pm 1.5$ & $0.7 \pm 0.7$ & N/A \\
\hline \multicolumn{12}{|l|}{ African Savanna } \\
\hline Andreae et al. (1998) & $\mathrm{F}$ & & $4.7 \pm 2.5$ & $0.8 \pm 0.5$ & $0.6 \pm 0.3$ & N/A & $1.2 \pm 0.2$ & $11 \pm 3.4$ & $2.7 \pm 1.2$ & $1.7 \pm 1.1$ & N/A \\
\hline Gaudichet et al. (1995) & $\mathrm{F}$ & N/A & N/A & N/A & N/A & 0.25 & 0.25 & 2.9 & 4.3 & 0.4 & N/A \\
\hline Cachier et al. (1995) & $\mathrm{F}$ & 65.0 & 8.0 & N/A & N/A & 2.0 & $<0.5$ & 4.0 & 6.0 & $<1.0$ & N/A \\
\hline Cachier et al. (1991) & $\mathrm{F}$ & 13.6 & 4.0 & N/A & N/A & N/A & 1.4 & N/A & 4.29 & 2.46 & N/A \\
\hline Maenhaut et al. (1996) & $\mathrm{F}$ & N/A & N/A & 0.4 & $<0.06$ & $<0.15$ & 0.06 & 9.7 & 6.2 & 0.0029 & 0.02 \\
\hline Maenhaut et al. (1996) & $\mathrm{S}$ & N/A & N/A & 0.13 & $<0.1$ & $<0.1$ & 0.35 & 2.3 & 1.8 & 0.04 & 0.03 \\
\hline \multicolumn{12}{|l|}{ Cerrado } \\
\hline Ferek et al. (1998) & $\mathrm{F}$ & $61 \pm 20$ & $7.5 \pm 4.0$ & $0.1 \pm 0.1$ & $0.5 \pm 0.3$ & N/A & $0.3 \pm 0.1$ & $1.7 \pm 1.0$ & $3.3 \pm 2.8$ & $0.9 \pm 0.5$ & N/A \\
\hline Ward et al. (1992) & $\mathrm{F}$ & N/A & N/A & N/A & N/A & 0.6 & 0.2 & 2.0 & 6.0 & 0.8 & 1.2 \\
\hline Ward et al. (1991) & $\mathrm{F}$ & 57 & 3.3 & N/A & N/A & 0.9 & 2 & 6 & 18 & 12 & 0.9 \\
\hline Yamasoe et al. (2000) & $\mathrm{F}$ & N/A & $12.6 \pm 6.8$ & $\sim 0.02$ & $\sim 0.04$ & bdl & $0.2 \pm 0.1$ & $2.2 \pm 0.16$ & $3.0 \pm 2.1$ & $0.1 \pm 0.1$ & $\sim 0.08$ \\
\hline Yamasoe et al. (2000) & S & N/A & $6.5 \pm 7.6$ & $\sim 0.01$ & $\sim 0.03$ & bdl & $0.3 \pm 0.2$ & $1.0 \pm 1.3$ & $1.3 \pm 1.7$ & $0.1 \pm 0.1$ & $\sim 0.05$ \\
\hline \multicolumn{12}{|l|}{ NA Temporate } \\
\hline Ward et al. (1991) & M & 50 & 5 & N/A & N/A & 0.3 & 0.4 & 0.3 & 1.0 & 0.8 & 0.1 \\
\hline \multicolumn{12}{|l|}{ Trop. Broadleaf } \\
\hline Ferek et al. (1998) & $\mathrm{F}$ & $53 \pm 20$ & $7.9 \pm 4.0$ & $\sim 0.04$ & $0.6 \pm 0.4$ & N/A & $1.0 \pm 1.0$ & $1.1 \pm 1.1$ & $4.8 \pm 4.5$ & $0.9 \pm 0.8$ & N/A \\
\hline Ward et al. (1992) & $\mathrm{F}$ & N/A & N/A & N/A & N/A & 0.1 & 1 & 2.7 & 5.5 & 1.0 & 0.1 \\
\hline Ward et al. (1991) & $\mathrm{F}$ & 50 & 10 & N/A & N/A & 3 & N/A & N/A & 2 & 5 & 0.9 \\
\hline Yamasoe et al. (2000) & $\mathrm{F}$ & N/A & $7.3 \pm 5.5$ & $\sim 0.01$ & $\sim 0.03$ & bdl & $0.3 \pm 0.2$ & $0.3 \pm 0.2$ & $0.8 \pm 0.6$ & $\sim 0.1$ & $\sim 0.03$ \\
\hline Yamasoe et al. (2000) & S & N/A & $3.9 \pm 1.9$ & $\sim 0.01$ & $\sim 0.01$ & bdl & $0.3 \pm 0.2$ & $0.2 \pm 0.1$ & $0.4 \pm 0.3$ & $\sim 0.06$ & $\sim 0.05$ \\
\hline Ferek et al. (1998) & $\mathrm{S}$ & $67 \pm 11$ & $5.3 \pm 2.0$ & $0.2 \pm 1.0$ & $0.3 \pm 0.3$ & N/A & $0.7 \pm 0.3$ & $1.0 \pm 1.3$ & $2.5 \pm 2.0$ & $0.6 \pm 0.7$ & N/A \\
\hline Ward et al. (1992) & $S$ & $\mathrm{Na}$ & $\mathrm{Na}$ & $\mathrm{Na}$ & $\mathrm{Na}$ & 0.1 & 0.2 & 0.6 & 2.3 & 0.3 & 0.1 \\
\hline \multicolumn{12}{|l|}{ Agricultural } \\
\hline Turn et al. (1997) & $\mathrm{F}$ & 31 & 18 & 0.64 & na & bdl & $1.6 \pm 0.05$ & $21+0.54$ & $14 \pm 0.33$ & & 0.017 \\
\hline de Zarate et al. (2000) & $\mathrm{F}$ & & & $0.18 \pm 0.05$ & $0.02 \pm 0.01$ & & $0.2 \pm 0.1$ & $1.0 \pm 0.1$ & $1.1 \pm 0.4$ & $0.04 \pm 0.01$ & \\
\hline
\end{tabular}

concentrations attributed to biomass burning have been very successful based solely on these trace species (e.g., Artaxo et al., 1994, 1998). The prevalence of potassium and chloride has made them favored smoke tracer species for receptor modeling (e.g., Calloway et al., 1989; Artaxo et al., 1994; Reid et al., 1998b), although in regions with more complicated aerosol chemistry such as Asia, co-linearity issues can prevent its use (Gao et al., 2003b). Other trace species, such as bromine and rubidium ( $<0.1 \%$ of particle mass) have also been found to correlate well with biomass burning particles (Artaxo et al., 1994).

\section{Thermodynamic properties}

Because of the effects smoke particles have on cloud microphysics, and the possible modulation of smoke particle optical properties by the uptake of water at higher relative humidity, the nature of the thermodynamic properties of smoke particles is of intense interest in the climate community. It has been established for decades that smoke particles can be very effective cloud condensation nuclei $(\mathrm{CCN})$ at supersaturations greater than $0.5 \%$ (e.g., Warner and Twomey, 1967; Hobbs and Radke, 1969; Eagan et al., 1974), and some can activate at supersaturations as low as $0.05 \%$ (Stith et al., 1981; Rogers et al., 1991) (For comparison, most marine stratocumulus have supersaturations on the order of $0.1 \%$, and values can exceed $1 \%$ for deep convection.). Similar studies on the high efficiency of smoke as CCN continue to this day (e.g., Ji et al., 1998; Reid et al., 1999b; Roberts et al., 2002).

Only $1 \%$ of the mass of an accumulation mode sized particle needs to be an electrolytic material in order to allow activation of a particle at $1 \%$ super saturation (Rogers et al., 1991). Recall from discussions in Sect. 4 that a large fraction of the organic compounds in smoke particles are watersoluble (e.g., Novakov and Corrigan, 1996a); hence it is not unreasonable that smoke particles are effective $\mathrm{CCN}$ at relatively low supersaturation. The presence of organic acids such as formate and acetate in smoke particles is more than sufficient to allow these particles to be efficient CCN (Yu, 2000). 
The efficiency of smoke particles to become cloud droplets is parameterized as either a number or mass efficiency ratio. The $\mathrm{CCN}$ efficiency is defined as the ratio of $\mathrm{CCN}$ to $\mathrm{CN}$ for a given supersaturation. Similarly, the CCN mass efficiency ratio is defined as the total number of particles that activate at per gram of material. Often these ratios are presented at $1 \%$ supersaturation (found only in rapidly developing cumuliform clouds). Laboratory studies of eucalyptus smoke by Hallett et al. (1989) and Rogers et al. (1991) showed that $>80 \%$ of all smoke particles can activate as $\mathrm{CCN}$ at supersaturations greater than $1 \%$. For smoke particles in Brazil, Ji et al. (1998) and Ji (personal communication) found similar $\mathrm{CCN} / \mathrm{CN}$ ratios of $\sim 95 \%, 70 \%$ and $20 \%$, for supersaturations at $1.15 \%, 0.30 \%$, and $0.15 \%$, respectively. CCN mass efficiency ratios presented in the literature are also consistent with values ranging from $\sim 5 \times 10^{13}$ to $\sim 2 \times 10^{14} \mathrm{CCN}$ per gram of smoke at 0.1 and $1 \%$ supersaturation, respectively (Warren and Twomey, 1967; Dinh et al., 1992; Hobbs et al., 1996).

It is also noteworthy that, for weakly soluble particles such as those in smoke, the traditional Köhler curves need to be modified for very low maximum supersaturations (Laaksonen et al., 1998). For such particles, the relationship between supersaturation and droplet radius can have several modes and can exist in a meta-stable state between two energy maxima. Under these circumstances current definitions for "activation" and "CCN" become ambiguous.

Despite the ability to behave as effective $\mathrm{CCN}$, fresh smoke particles have also been shown to have relatively small hygroscopic growth at high relative humidity. There have been few studies that record the shift in size as a function of RH; instead most record the increase in light scattering. Light scattering hygroscopicity is discussed in more detail in Part 3 of this series of manuscripts, but a short discussion is given here. Kotchenruther and Hobbs (1998) found that light scattering increased by a factor of $1.15-1.3$ between dry and $80 \%$ relative humidity conditions (compared to greater than a factor of two for sulfate). More recently, Magi and Hobbs (2003) found higher values for African savanna smoke on the order of 1.4. A similar inference was made by Formenti et al. (2002) for Canadian smoke transported to the Mediterranean Sea. For particles in the size range of smoke (volume median diameter of $\sim 0.3 \mu \mathrm{m}$ ), light scattering in the mid visible is linear with particle volume. Hence, these values would correspond to a $<12 \%$ increase in size.

This dichotomy between high CCN efficiency and low hygroscopicity is theoretically predicted. Köhler theory demonstrates that a particle's CCN efficiency is related to its size and solubility (e.g., see Pruppacher and Klett, 1997). The relative importance of these factors is determined by the maximum supersaturation reached in the cloud. The Köhler theory suggests that particle chemistry is not as important as particle size in determining the CCN efficiency of particles in clouds with supersaturations greater than $0.5 \%$, such as cumulus clouds. For any particle to function as a $\mathrm{CCN}$, it must have the capability to form a $\mathrm{H}_{2} \mathrm{O}$ monolayer on its surface. Once a monolayer of water has formed, the particle will form a cloud drop (perhaps unstable by not overcoming the energy barrier for free growth, but a drop nonetheless). In the extreme example, consider that almost every aerosol particle in the atmosphere has some hygroscopicity after it has aged in a smoky environment, as gas-to-particle condensates tend to condense on almost everything. Hence at least a water monolayer can be formed on most interstitial aerosol particles in a cloud. Once the monolayer has formed in moderate supersaturation, the initial particle size significantly influences if that particle will fully activate and pass the Köhler thermodynamic maximum. It has been suggested that even "unsoluble" dust particles can become efficient CCN after being transported in a polluted air mass (Levin et al., 1996). In the case of smoke, we have an intermediate case where the particle already has some hygroscopicity to speak of. Hence we expect good CCN efficiency at moderate high supersaturations. We must also consider that even in cases when supersaturations are low, smoke particles are typically transported in such quantities that the environment is $\mathrm{CCN}$ rich and the Twomey effect is still significant.

\section{Regional smoke characteristics}

In the previous sections of this review, we have discussed the properties of freshly generated smoke particles. However, smoke particles always undergo some form of physical change or evolution during transport. At the very least, the size distribution of smoke particles must be modified during the atmosphere's natural wet and dry removal processes. In this section we review the literature on the nature of smoke particle aging and discuss the physical and chemical properties of regional smoke.

Like any aerosol particles, there are a variety of mechanical, chemical and thermodynamic processes that can alter smoke properties. Under most circumstances, measurements of the characteristics of fresh smoke plumes and laboratory burns as described in previous sections cannot be assumed to be applicable to the aged smoke that is of most interest to the global climate and regional air quality communities. Given that the large smoky hazes are a result of numerous fires, each with their own characteristics, and that the relative amount of flaming versus smoldering combustion that feed these hazes is uncertain, comparisons of fresh and aged smoke are by no means straightforward.

\subsection{Properties of aged smoke particles}

Table 4 lists some reported smoke particle size measurements in regional or aged smoke. Here we include in-situ measurements as well as values from inversions presented by Dubovik et al. (2002) and Eck et al. (2003) (other inversion values are discussed in the Part 3 of this series by Reid 
Table 4. Measured particle size parameters for aged and regional smoke. OPC=Optical Particle Counter; DMPS=Differential Mobility Particle Sizer; IMP=Impactor; INV Sun/sky inversion.; CMD=Count Median Diameter; VMD=Volume Median Diameter; $\sigma_{g c}=$ geometeric standard deviation of the number distribution; $\sigma_{g v}=$ geometeric standard deviation of the volume distribution. The only values from inversions given are those from the Dubovik and King (2000) inversion. A discussion of the complete set of inversion data sets is presented in Part III of this series (Reid et al., 2005).

\begin{tabular}{|c|c|c|c|c|c|c|}
\hline Reference & Method & Region & CMD & $\sigma_{g c}$ & VMD & $\sigma_{g v}$ \\
\hline \multicolumn{7}{|l|}{ Africa } \\
\hline Anderson et al. (1996) & OPC & Africa Savanna & $0.22 \pm 0.03$ & & & \\
\hline Dubovik et al. (2002) & INV & South Africa & & & 0.29 & $\sim 1.5$ \\
\hline Haywood et al. (2003a) & $\mathrm{OPC}$ & South Africa & & & 0.30 & $\sim 1.35$ \\
\hline Le Canut et al. $(1996)^{a}$ & OPC & South Africa & $0.12-0.25$ & & $0.30 \pm 0.08$ & \\
\hline Eck et al. $(2003)^{b}$ & INV & Zambia & & & 0.34 & 1.5 \\
\hline \multicolumn{7}{|l|}{ North America } \\
\hline Hobbs et al. (1996) & DMPS & Temperate forest & $0.19 \pm 0.03$ & $\sim 1.7$ & $0.34 \pm 0.02$ & $\sim 1.7$ \\
\hline Radke et al. (1991) & OPC & Temperate Forest & & & $0.34-0.38$ & \\
\hline Dubovik et al. (2002) & INV & Canada & & & 0.33 & $\sim 1.55$ \\
\hline Eck et al. $(2003)^{b}$ & INV & NE North America & & & 0.40 & 1.4 \\
\hline \multicolumn{7}{|l|}{ South America } \\
\hline Anderson et al. (1996) & OPC & Brazil Cerrado & $0.23 \pm 0.03$ & & & \\
\hline Andreae et al. (1988) & OPC & Amazonia & & & $\sim 0.3$ & \\
\hline Dubovik et al. (2002) & INV & Amazonia/Cerrado & & & 0.30 & $\sim 1.55$ \\
\hline Echalar et al. (1998) & IMP & Amazonia & & & $0.175-0.33$ & $\sim 1.5$ \\
\hline Eck et al. $(2003)^{b}$ & INV & Brazil & & & 0.36 & 1.35 \\
\hline Reid et al. (1998b) & DMPS & Brazil 1 day old & $0.12 \pm 0.03$ & $1.8 \pm 0.15$ & $0.29 \pm 0.05$ & $1.61 \pm 0.2$ \\
\hline Reid et al. (1998b) & OPC & Brazil 1 day old & $0.14 \pm 0.03$ & $1.71 \pm 0.16$ & $0.26 \pm 0.02$ & $1.35 \pm 0.06$ \\
\hline Reid et al. (1998b) & DMPS & Brazil 2-3 days old & $0.18 \pm 0.03$ & $1.65 \pm 0.16$ & $0.35 \pm 0.05$ & $1.49 \pm 0.09$ \\
\hline Reid et al. (1998b) & OPC & Brazil 2-3 days old & $0.21 \pm 0.02$ & $1.55 \pm 0.07$ & $0.30 \pm 0.02$ & $1.49 \pm 0.09$ \\
\hline \multicolumn{7}{|l|}{ Other } \\
\hline Fiebig et al. (2003) & OPC & Well aged Canadian smoke in Europe & $0.34 \pm 0.03$ & $1.3 \pm 0.1$ & & \\
\hline Formenti et al. (2002) & OPC & Mediterranean & $0.195 \pm 0.01$ & 1.53 & & \\
\hline
\end{tabular}

${ }^{a}$ Sub-micron, bi-modal number distribution.

${ }^{b}$ Eck et al. (2003) gives the largest particle sizes found in each region.

et al., 2005). Inverted size distributions for smoky hazes from AERONET are presented in Fig. 2 (for AODs=0.7 at $440 \mathrm{~nm}$ ). Typically, smoke particles increase in size with age and a diurnal cycle can even be detected (Reid et al., 1999a). For example, aged particles typically have CMDs ranging from $0.12-0.23 \mu \mathrm{m}$, with a mean around $0.18 \mu \mathrm{m}$ (compared to $\sim 0.12 \mu \mathrm{m}$ for fresh particles). Similarly, volume median diameters (VMD) are also larger in aged smoke and range from $0.26-0.35 \mu \mathrm{m}$ with a mean around $0.30 \mu \mathrm{m}$. Reports of geometric standard deviations are also somewhat narrower for aged smoke. Aged particles are also more spherical than fresh counterparts. Ruellan et al. (1999) found that only $34 \%$ of smoke particles from fresh fires in Africa had a shape ratio (highest to smallest dimension) less than 2.5. compared to $78 \%$ meeting this criterion for more aged smoke. Similar results were found by Martins et al. (1996) and Posfai et al. (2003).

However, like fresh smoke particles, aged smoke particles in North American forest fires do appear to be larger than those in the tropics and sub tropics of Africa and South America. This is not only due to fire intensity and fuel issues

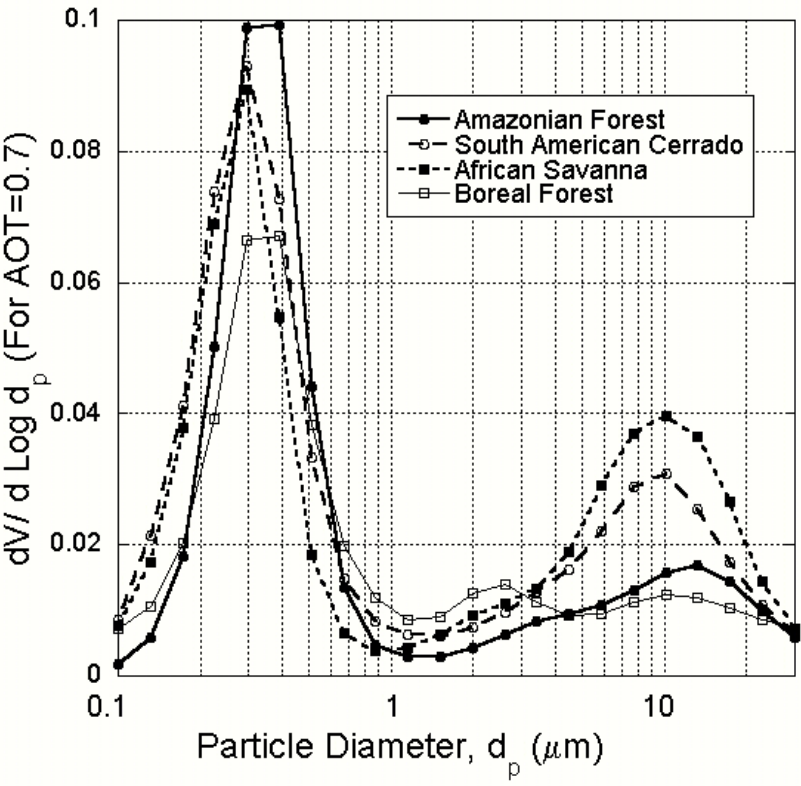

Fig. 2. Retrieved AERONET particle size distributions for a $440 \mathrm{~nm}$ Aerosol Optical Depth (AOT) of 0.7 . 
but also in part due to the fact that in areas of intense regional burning such as in the tropics, fresh smoke is constantly being ejected into the air mass by numerous fires. The largest documented size distributions are in Eck et al. (2003) which presents the highest values found from inversions within the AERONET network. For high concentration aged plumes, volume median diameters (VMDs) as high as $0.5 \mu \mathrm{m}$ are found. The highest measured particle count median diameter (CMD) was $0.34 \mu \mathrm{m}$ for Canadian smoke measured in the Mediterranean (Formenti et al., 2002). However, even these values are small compared to "blue moon" events where sizes larger than $0.7 \mu \mathrm{m}$ are required for extinction in the red to overtake that in the blue (last documented by Robert Wilson in 1950 where a large Canadian forest fire plume was observed in Great Britain - Bohren, 1987).

Table 5 lists reports of smoke particle organic carbon, black carbon, and key trace inorganic species for aged regional smoke. Only values where biomass-burning smoke constituted $>75 \%$ of the fine mode aerosol are presented. Like fresh smoke, there is a significant variability in the quantity of black carbon and trace elements present. A portion of this variability is no doubt due to the presence of other species in the atmosphere. However, receptor modeling in regions impacted by smoke such as multivariate analysis (e.g., Maenhaut et al., 1996), and principal component analysis (e.g., Artaxo et al., 1994, 1998; Echalar et al., 1998; Pereira et al., 1996; Reid et al., 1998b) has little trouble extracting the smoke apportionment. Understandably, these methods easily extract the key tracer species for smoke, principally black carbon, potassium, and secondary sulfate. Occasionally, there are some co-linearity issues with biogenic particles, and species like calcium and magnesium may be mistaken in the biomass burning apportionment.

Differences in particle chemistry between fresh and aged smoke take two principal forms. Comparison of Table 5 to Table 3 suggests that the two principal tracers for smoke, potassium and black carbon, tend to make up a smaller mass fraction of aged smoke particles. This is in part due to the significant contribution of smoldering combustion to the total production budget. However, aged smoke particles show a significant enrichment of species associated with secondary aerosol production such as sulfur in the form of sulfate. In addition, several studies have shown significant enrichments on the order of a factor of 3 to 5 of other inorganic secondary species in aged smoke, like ammonium and nitrates (Reid et al., 1998b; Formenti et al., 2003). These species can increase total particle mass by as much as $10 \%$ (Reid et al., 1998b). Further, $\mathrm{KCl}$ in the cores of particles can rapidly evolve to $\mathrm{KSO}_{4}$ and $\mathrm{KNO}_{3}$ ( $\mathrm{Li}$ et al., 2003). Organic acids such as oxalate, formate, and acetate are also greatly enriched through secondary processes. In fresh smoke these species constitute less than $1 \%$ of particle mass. However, in aged plumes each of these species can account for more than 3\% of mass (Andreae, et al., 1988; Reid et al., 1998b; Formenti et al., 2003). More recent studies with higher numbers of identifiable species such as those of Gao et al. (2003a) have found glutaric, succinac, and malonic acids in concentrations that rival or exceed these more commonly reported species. In sum, organic species can increase particle mass by up to $40 \%$, with roughly half due to condensation near the fire source and the remainder from other processes during long term aging (Reid et al., 1998b). The fraction of semi-volatile compounds as a whole may also be enriched by up to $50 \%$ during aging (Eatough et al., 2003).

Particle aging also affects particle hygroscopicity and $\mathrm{CCN}$ efficiencies. Any mechanism that increases particle size, by default increases the particle's CCN efficiency. The secondary production of soluble material such as sulfates or polar organic compounds such as organic acids will further increase the hygroscopicity and CCN efficiency of smoke particles (Rogers et al., 1991; Kotchenruther and Hobbs, 1998). Yu (2000) notes that despite the fact that $99 \%$ of acetate and formate in the atmosphere is in the gas phase, the $1 \%$ of condensate on the particles is enough to allow smoke particles to be efficient CCN. Organic coatings such as glutaric acid have been shown to increase the $\mathrm{CCN}$ efficiency on already highly hygroscopic ammonium sulfate particles. It is then reasonable to assume that, as organic acids are produced in aging smoke plumes (as discussed in the next section), the CCN efficiency and hygroscopicity of smoke particles will further increase with time.

For a relative humidity shift of 30 to $80 \% \mathrm{RH}$, Kotchenruther and Hobbs (1998) found mean hygroscopic growth factors for light scattering on the order of 1.3-1.5 for aged smoke (versus $\sim 1.1-1.3$ for those freshly generated). Based on the formation of organic acids discussed above and an inorganic chemical reaction suggested by Li et al. (2003) is consistent with the idea that individual particle chemistry alone should increase hygroscopicity in time. More recent investigations suggest even higher hygroscopic light scattering growth factors $(>1.6$ at $80 \% \mathrm{RH}$ by Kreidenweis et al., 2001 and Magi and Hobbs, 2003). While hygroscopic growth factor should change with time with any chemical evolutionary process, it is unclear to what extent higher values are related to the smoke particles themselves or to the presence of other more hygroscopic anthropogenic pollutants in the aerosol mixture. For example, recently Langmann and Graff (2003) suggest values in Indonesia are inflated due to the presence of volcanic sulfur.

\subsection{Particle evolution processes}

Evidence suggests that most particle growth in size and mass occurs on fairly short time scales. For example, Hobbs et al. (1996) reported that over a two-hour period for one very large and intense fire, the count median diameter for freshly generated smoke increased from 0.16 to $0.28 \mu \mathrm{m}$, and the volume median diameter increased from 0.25 to $0.38 \mu \mathrm{m}$. Abel et al. (2003) found extremely rapid changes in smoke particle microphysics in as little as $2 \mathrm{~h}$ 
Table 5. Particle composition mass percentages for various regions heavily impacted by smoke.

\begin{tabular}{|c|c|c|c|c|c|c|c|c|c|c|}
\hline Reference & $\mathrm{OC}$ & $\mathrm{BC}$ & $\mathrm{Na}$ & $\mathrm{Mg}$ & $\mathrm{Si}$ & $\mathrm{S}$ & $\mathrm{Cl}$ & $\mathrm{K}$ & $\mathrm{Ca}$ & $\mathrm{Fe}$ \\
\hline \multicolumn{11}{|c|}{ South America-Rhondonia } \\
\hline Andreae et al. (1988) & $66 \pm 17$ & $13 \pm 5$ & $1 \pm 0.5$ & & & $3.7 \pm 1.6$ & $0.6 \pm 0.4$ & $3.3 \pm 1.8$ & & \\
\hline Artaxo et al. (1994) & & & & & 0.4 & 2 & 0.02 & 1.5 & 0.06 & 0.2 \\
\hline Artaxo et al. (1998) & & 7 & 0.06 & 0.3 & 1.1 & 1.4 & 0.15 & 1.5 & 0.7 & 0.3 \\
\hline Echalar et al. (1998) & & 12.2 & & 1.0 & 1.1 & 2.0 & 0.14 & 2.6 & 0.9 & 0.42 \\
\hline Pereira et al. (1996) & & $2.5 \pm 1.6$ & & & $1.5 \pm 1.4$ & $1.4 \pm 0.5$ & $0.5 \pm 0.7$ & $2.2 \pm 2.0$ & $0.4 \pm 0.3$ & $0.4 \pm 0.3$ \\
\hline Reid et al. (1998b) & & $6 \pm 3$ & $0.25 \pm 0.3$ & $0.07 \pm 0.04$ & & $2.0 \pm 0.5$ & $0.1 \pm 0.2$ & $1.8 \pm 0.6$ & $0.2 \pm 0.3$ & $0.5 \pm 0.3$ \\
\hline \multicolumn{11}{|c|}{ South America: Mato Grosso } \\
\hline Artaxo et al. (1994) & & & & & 0.4 & 3 & 0.1 & 3 & 0.2 & 0.9 \\
\hline Reid et al. (1998b) & & 8 & $0.1 \pm 0.3$ & $0.2 \pm 0.3$ & & $0.4 \pm 0.3$ & $0.12 \pm 0.2$ & $1.5 \pm 0.7$ & $0.45 \pm 0.3$ & $0.5 \pm 0.3$ \\
\hline \multicolumn{11}{|l|}{ South Africa } \\
\hline Formenti et al. (2003) & 42 & $7^{a}$. & 1.29 & 4.5 & & $4.3^{b}$ & 0.2 & 4.1 & 0.34 & \\
\hline Maenhaut et al. (1996) & & 11 & 5.7 & 1.0 & 1.7 & 10.0 & 0.6 & 2.3 & 0.4 & 0.5 \\
\hline Ruellan et al. (1999) & $36 \pm 3$ & $7^{a}$ & & & & $2.5 \pm 2.0$ & & $1.1 \pm 0.4$ & & \\
\hline
\end{tabular}

${ }^{a}$ Calculations were presented as a ratio to black carbon. For comparative purposes, we assume black carbon in $7 \%$ of aerosol particle mass.

${ }^{b}$ Based on $\mathrm{SO}_{4}^{=}$measurements.

after emission. Conversely, during the TRACE-A study Anderson et al. (1996) found that on average, smoke particles measured over the central South Atlantic Ocean had size distributions not greatly different from those measured over the South American and African continent. Cases of intermediate time scale growth can be found in Radke et al. (1995) and Reid et al. (1998b). There are numerous reports of rapid increases in smoke particle size in the first 30 to 90 min after emission, and more modest increases on time scales of days. These also correspond to a period of extremely high ozone production (e.g., Hobbs et al., 1996; Jost et al., 2003).

Excluding scavenging processes, studies on smoke particle evolution and growth have focused on Brownian coagulation in dispersing plumes, and gas-to-particle conversion and exchange. There have been theoretical studies of the effects of coagulation on accumulation mode particles applicable to evolving smoke plumes (e.g., Turco and Yu, 1997), as well as some performed in the context of nuclear winter (e.g., Penner and Porch, 1987).

The theory of Brownian coagulation for an aerosol is well defined, and both simplified and full descriptions can be found in numerous sources (e.g., Lee and Chen, 1984; Hinds, 1982; Seinfeld and Pandis, 1998). The growth rate of particles due to coagulation depends heavily on environmental factors, including average smoke particle size, concentration, ambient temperature and pressure. Coagulation rates are roughly proportional to the square of concentration, and instantaneous growth rates in particle volume median diameter are roughly linear with concentration (Lee and Chen, 1984). Immediately after emission, smoke particle concentrations and temperatures are high, and particle growth is consequently rapid. For example, Reid et al. (1998b) found that for moderate sized fires in Brazil at $500 \mathrm{~m}$ height with particle concentrations on the order of $150000 \mathrm{~cm}^{-3}$ and average CMD of $0.12 \mu \mathrm{m}$, instantaneous growth rates are $\sim 0.01 \mu \mathrm{m}$ every $45 \mathrm{~min}$. Just above the flame zone, particle concentrations and temperatures are much larger, and the coagulation rate could easily be an order of magnitude higher. Conversely, after a few hours when the plumes have dispersed into regional smoky hazes with concentrations of $5000-10000 \mathrm{~cm}^{-3}$, growth rates slow to $0.015-0.03 \mu \mathrm{m}$ per day. These calculations indicate that after a plume has dispersed into a regional haze or is undergoing long-range transport, particle coagulation is the significant mechanism for particle growth over long enough timescales.

Gas-to-particle conversion can be as important as coagulation in influencing particle size during the smoke aging process. Recent discussions on the effect of simultaneous condensation and coagulation on accumulation mode particle size can be found in Turco and Fangqun (1999). For smoke particles, gas-to-particle conversion has at least three components: 1) Near source condensation of primary low vapor pressure organics, 2) production of inorganic particulate matter, and 3) gas-to-particle conversion of organics.

Low vapor pressure organic species, such as long chain hydrocarbons, condense onto smoke particles immediately after the plume leaves the flame zone. Indeed, as discussed in Sect. 2, the smoke particle formation mechanism itself is a condensational process. As the smoke plume rises, mixes, and cools, organic species begin to condense on the preexisting particles. It is likely that it takes several minutes for the vapor/particle phase partition for long chained hydrocarbons 
to come into equilibrium. For example, Hobbs et al. (1996) and Martins et al. (1996) showed that for a large intense prescribed burn, smoke particles grew by a factor of two in volume between emission and $\sim 2 \mathrm{~h}$ down wind. Electron microscopy images taken in isolated evolving plumes by Martins et al. (1996) showed significant morphological changes from irregular particles to coated spheres or collapsed aggregates in these same aging plumes. A similar growth effect was observed by Reid et al. (1998b) and Abel et al. (2003). Babbitt et al. (1997) reported that smoke particle emission factors derived from particles collected on towers were half that of those derived from aircraft measurements a few hundred meters above the fire. This may indicate that the condensation of high molecular weight hydrocarbons occurs rapidly following emission.

As noted in the earlier reports, geometric standard deviations in regional smoky hazes are smaller than fresh smoke. There are several reasons for this (both physical and artifact). First, as noted by McMurry and Wilson (1982) and Turco and Fangqun (1999) condensational processes will narrow particle volume distributions. Eck et al. (2003) found similar trends of very low geometric standard deviations for very thick smoke plumes. Hence, reported data are consistent with the condensation hypothesis. It is also noteworthy that, to some extent, this may be attributable to instrument artifact. The two smallest standard deviations of volume distributions, $(\sim 1.35)$, were reported by Reid et al. (1998b) and Haywood et al. (2003), both using wing mounted optical particle counters (PCASPs). The number distributions presented in these manuscripts were very similar. These narrow values are unusual compared to other aerosol size distributions. Simultaneous measurements with a differential mobility analyzer by Reid et al. (1998b), however, showed a much more lognormal shape and a corresponding geometric standard deviation of 1.55. As is discussed in the Part 3 of this series of manuscripts, the narrow geometric standard deviation of the volume distribution may be an optical artifact of the PCASP instrument, even after index of refraction corrections are made.

The gas-to-particle conversion of inorganic species such as sulfate, ammonium and nitrate during plume aging is another secondary particle production mechanism. Reid et al. (1998b) found that well aged smoke particles in Brazil may increase in particle mass by $5-10 \%$ by the formation of sulfate, ammonium, and nitrate. Much of this formation is from primary gas emissions of $\mathrm{SO}_{2}, \mathrm{NO}_{\mathrm{x}}$ and $\mathrm{NH}_{3}$, although there can be an impact from industrial sources (Kreidenweis et al., 2001). Sulfate leads these species with a maximum particle mass growth of $\sim 8 \%$. One of the regulating factors for the secondary production of sulfate is the presence of clouds. Gas phase oxidation of $\mathrm{SO}_{2}$ is fairly slow, on the order of a week (Seinfeld and Pandis, 1998). Reid et al. (1998b) found that in regions with locally generated smoke, smoke particle sulfate concentrations were no different than fresh smoke. In contrast, areas with the highest con- vective cloud activity showed the highest production of these species. As it is typical for high ozone concentrations to form in evolving smoke plumes (Delany et al., 1985; Hobbs et al., 1996), there can be adequate oxidation potential in the environment for secondary processes to occur.

Although contributing a smaller amount to secondary particle production $(\sim 2-3 \%)$, ammonium is an important indicator species. Ammonia is released in large quantities by biomass burning (Hegg et al., 1988) and hence ammonium production is expected to occur in aging plumes. Reid et al. (1998b) found that ammonium correlated with smoke particle size better than any other chemical species. This fact is important because ammonium concentrations measured on filters provide a measure of ammonium in the air, and the amount of ammonium required to bring the aerosol to a neutral $\mathrm{pH}$. Also, during sample extraction prior to IC analysis, amines, amides, and possibly nitriles can be hydrolyzed to ammonium and an organic acid (Finlayson-Pitts and Pitts, 1986). Thus, ammonium production may also be a confounding variable acting as a simple aging indicator, and hence correlated with another mechanism such as coagulation or an unrelated chemical process.

The least understood gas-to-particle conversion mechanism affecting smoke properties involves the secondary production of organic species. Organic acid vapor and particle production has been observed frequently in photochemical smog (Hartmann et al., 1989; Madronich et al., 1990; Satsumabayashi et al., 1990) as well as in aging smoke plumes (Andreae et al., 1988; Helas et al., 1992; Reid et al., 1998b; Ruellan et al., 1999; Hobbs et al., 2003; Gao et al., 2003a). The formation pathways are not well understood. Again, ammonium may be a key indicator. Reid et al. (1998b) found that ammonium was highly correlated with oxalate, but not with sulfate, suggesting ammonium is related to organic acid formation. Much of the organic acid vapors released by fires, or photochemically produced in smoke plumes, are likely to be formed by ternary nucleation (in haze particle), by heterogeneous reactions in cloud drops, or, possibly, even by gasphase reactions. Reid et al. (1998b) suggests that over the course of several days, particle mass can grow by as much as $10-30 \%$ by this mechanism. Hobbs et al. (2003) found evidence of homogenous nucleation of secondary particles in evolving smoke plumes- a condition thatoccurs only at the highest supersaturation of these species.

Particle yields for organic gases are typically low. For example Forstner et al. (1997) have shown that in a smog chamber, carbon yields from even the most reactive NMHC species is less than 5\%. However, recent studies have shown that oxygenated hydrocarbons account for more than $40 \%$ of the non-methane hydrocarbon emissions by biomass burning (Koppmann et al., 1997). Due to their high reactivity, these species are typically unreported and could be a large reservoir for secondary aerosol production. Additionally, there is the possibility that a synergistic relationship for secondary aerosol production exists between biomass burning 
and natural biogenic emissions. The presence of water on smoke particles also likely increases reaction rates on the surface of smoke particles. As smoky hazes in Africa are considerably drier than in South America $(\sim \mathrm{RH}<35 \%$ and $\sim 70 \%$, respectively), there may be a difference in secondary production.

Often organic vapors are in equilibrium between vapor and condensed phases (Eatough et al., 2003; Jacobson et al., 2000). The species generated by gas-to-particle organic acids and nitrate species can be in fast equilibrium between the gas and condensed phases, with the overwhelming amount being in the gas phase. This can hold true for some primary organic species such as other organic acids and alcohols. Given that $35 \%$ of aged smoke particle mass is attributable to semivolatile organic compounds, there is some potential for particle volume modulation. Some studies in Africa have stated that particles shrink in mass substantially due out-gassing (notably Liousse et al., 1995 and reproduced by Formenti et al., 2003) based on an increase in the BC/OC ratio with time- which is contrary to the many other reports of mass growth discussed above. This is despite the fact that Formenti et al. (2003) also found a significant increase in the light scattering to $\mathrm{CO}$ ratio at rates much too high to attribute simply increasing mass scattering efficiencies due to coagulation alone. However, this is hypothesized based solely on observations of an increase in the $\mathrm{BC}$ to $\mathrm{OC}$ ratio using thermal techniques. Given the potential of significant positive organic artifact when using thermal methods in high intensity smoke plumes, this hypothesis requires substantiation with more complete gravimetric and sampling protocols. Regardless, this is a very unusual effect and requires further study.

\section{Estimates of particle emission factors}

Forward modeling of smoke particle production into the atmosphere requires the use of emission functions in units of mass of particles produced per unit fuel burned. Most particle emission factors presented in the literature are derived from empirical data based on the carbon mass balance method of Ward et al. (1982). The underlying premise of this method is that all of the carbon combusted in a fire is emitted into the measurable portions of a smoke plume in five forms of carbon: $\mathrm{CO}_{2}, \mathrm{CO}, \mathrm{CH}_{4}$, non-methane hydrocarbons, and particulate carbon. The emission factor of a species, $n$, is then calculated from the ratio of the mass concentration of that species to the total carbon concentration emitted in the plume:

$$
E F_{n}=\frac{[\mathrm{n}]}{[\mathrm{C}]_{\mathrm{CO}_{2}}+[\mathrm{C}]_{\mathrm{CO}}+[\mathrm{C}]_{\mathrm{CH}_{4}}+[\mathrm{C}]_{\mathrm{NMHC}}+[\mathrm{C}]_{p c}}
$$

Thus, as shown above the emission factor is expressed in units of mass of species $n$ emitted per unit mass of carbon burned. To convert this emission factor to the more commonly used grams $\mathrm{n}$ produced per kg dry matter burned,
$E F_{n f}$ is multiplied by the mass fraction of carbon in the fuel $(\sim 50 \%)$.

Emission factor data sets have been generated from measurements in a variety of environments from laboratory burns, ground-based fire towers, and aircraft measurements. A summary of emission factor measurements for flaming, smoldering and unspecified or mixed fire phase is presented in Table 6 (again, all fires are really "mixed phase," and we use the modified combustion efficiency values of 0.90 to separate the predominant phase)). As a whole, all studies show a similar trend with particle emission factors logically increasing with decreasing combustion efficiency (that is with increasing relative amounts of smoldering combustion). For example, the average particle EF for all flaming combustion measurements is $\sim 18 \mathrm{~g}$ per $\mathrm{kg} \mathrm{C}$ burned versus $\sim 68 \mathrm{~g}$ per $\mathrm{kg} \mathrm{C}$ burned for smoldering combustion, roughly a factor of three difference (or $\sim 9$ and $34 \mathrm{~g} \mathrm{~kg}^{-1}$ dry matter burned for flaming and smoldering combustion, respectively). What is more interesting is that measured particle EFs vary so widely. The standard deviation of the mean values for all flaming and smoldering is $\sim 15$ and $\sim 60$ g per kg C burned, respectively, or more than $75 \%$ of the mean value. Aside from instrumentation error/uncertainty (which can be substantial on individual samples), the bulk of the variability in Table 6 is likely due to 3 factors: Fuel type/characteristics, fire size/intensity, and sampling bias. As will be shown, these factors are not necessarily independent.

The largest amount of variability in Table 6 can be accounted for by fuel or biome type. Most grass/shrub ecosystem fire reports tend to have similar emission factors, on the order of 6-15 g per $\mathrm{kg} \mathrm{C}$ burned. For the grass-shrub category, fuel is typically small and dry, fuel loadings are comparatively low, and thus burning is dominated by the flaming phase. Fire lines tend to be spatially thinner and well ventilated with consequently high combustion efficiencies (e.g., Ward et al., 1996). In contrast, forest combustion conditions are markedly different with larger fuel, typically larger fire lines, higher fuel loadings and consequently higher intesity. Further, fuel is more likely to be wetter in forested regions with both excess water and with more organic compounds and oils, such as long chain hydrocarbons and sugars in sap, and terpenes in the leaves. Consequently, flaming phase combustion of forested fuels is two to three times more efficient at producing particles per gram of carbon burned than that of grass/shrub fuels ( $\sim 27 \pm 14$ g per $\mathrm{kg} \mathrm{C}$ burned). The fact that more smoldering combustion gets entrained into large plumes also increases the "flaming" emission factor.

Some of the variance in forested fuel can also be found between tropical and mid latitude forests. The 3 highest emission factors for flaming combustion come from northern latitude studies and fuels (Patterson et al., 1986; Ward and Hardy, 1991; Hobbs et al., 1996), with fine-mode particle emission factors greater than $30 \mathrm{~g}$ per $\mathrm{kg} \mathrm{C}$ burned. In comparison, the 2 studies of tropical forest burns yield flaming phase emission factors on the order of $10-15 \mathrm{~g}$ per $\mathrm{kg}$ 
Table 6. Reported emission factors in units of $\mathrm{g}$ per $\mathrm{kg} \mathrm{C}$ burned. In units of g per kg fuel burned divide values by $\sim 2$. MCE=Modified Combustion Efficiency.

\begin{tabular}{|c|c|c|c|c|c|}
\hline & Description & \# Fires & Flaming MCE $>0.9$ & Unspec./Mixed & Smoldering $\mathrm{MCE}<0.90$ \\
\hline \multicolumn{6}{|l|}{ Savanna/Grassland } \\
\hline Andreae et al. (1998) & African Savanna & 4 & $6 \pm 1.5$ & & \\
\hline Cachier et al. (1995) & African Savanna & $15 / 7 / 3$ & $10 \pm 4$ & $30 \pm 8$ & $60 \pm 22$ \\
\hline Ferek et al. (1998) & Brazilian Grass & 6 & $16 \pm 7$ & & \\
\hline Gaudichet et al. (1995) & African Savanna & 1 & 18 & & \\
\hline Le Canut et al. (1996) & African Grasslands & 7 & $3.4 \pm 0.4$ & & \\
\hline Le Canut et al. (1996) & African Savanna & 9 & $6.4 \pm 2.8$ & & \\
\hline Ward et al. (1988) & Saw Grass & 1 & $<20$ & & \\
\hline Ward et al. (1996) & African Savanna & 10 & $11 \pm 3$ & & \\
\hline \multicolumn{6}{|l|}{ Cerrado/Scrub Forest } \\
\hline Ferek et al. (1998) & Brazilian Cerrado & 6 & $10 \pm 4$ & & \\
\hline Le Canut et al. (1996) & African Dambos & 2 & $15.2 \pm 1.6$ & & \\
\hline Sinha et al. (2003) & African Brush/Woodland & 7 & $20 \pm 15$ & & \\
\hline Ward et al. (1992) & Brazilian Cerrado & 1 & 9 & & \\
\hline \multicolumn{6}{|l|}{ Tropical Forest } \\
\hline Ferek et al. (1998) & Brazilian Tropical Forest & $6 / 6$ & $17 \pm 8$ & & $27 \pm 11$ \\
\hline Ward et al. (1992) & Amazon Deforestation & 2 & $10 \pm 5$ & & \\
\hline \multicolumn{6}{|l|}{ Temperate/Boreal } \\
\hline Cofer et al. (1989) & Canadian Boreal & 1 & & $40 \pm 30$ & \\
\hline Hobbs et al. (1996) & Temperate Forest & $3 / 1$ & $58 \pm 10$ & & 83 \\
\hline Nance et al. (1993) & Alaskan Wildfire & 3 & $36 \pm 8$ & & \\
\hline Radke et al. (1991) ${ }^{a}$ & North Amer. Slash & 14 & & $30 \pm 22$ & \\
\hline Reinhardt (unpublished] ${ }^{b}$ & North Amer. Forest & N/A & $\sim 30$ & & $\sim 120$ \\
\hline Sandberg et al. $(1975)^{c}$ & North Amer. Temperate Forest & N/A & $15 \pm 8$ & & $20 \pm 8$ \\
\hline Stith et al. (1981) & North Amer. Temperate Forest & 3 & $24 \pm 8$ & & \\
\hline Ward et al. (1988) & North Amer. Logging Slash & $5 / 1 / 5$ & $16 \pm 8$ & $40 \pm 20$ & $30 \pm 3$ \\
\hline Ward and Hardy (1991) & North Amer. Presc. Slash & N/A & $22 \pm 5$ & & $34 \pm 6$ \\
\hline Woods et al. (1992) & North American Presc. Forest & 3 & & $\sim 14$ & \\
\hline \multicolumn{6}{|l|}{ Other } \\
\hline Einfeld (1991) & North Amer. Wetlands-Presc & 2 & $6 \pm 2$ & & $20 \pm 6$ \\
\hline Susott et al. (1991) & North Amer. Wetlands & $3 / 1 / 3$ & $28 \pm 3$ & 28 & $32 \pm 8$ \\
\hline \multicolumn{6}{|l|}{ Wind Tunnel } \\
\hline Dasch (1982) & Fireplaces & N/A & & $10 \pm 5$ & \\
\hline Jenkins et al. (1991) & Straw- Wind Tunnel & 2 & $\sim 7$ & & \\
\hline Patterson et al. (1986) & Lab Pine Needle Burns & 14 & $30 \pm 36$ & $108 \pm 30$ & $180 \pm 40$ \\
\hline Turn et al. (1997) & Herbaceous-Wind Tunnel & 16 & $\sim 10$ & & \\
\hline Turn et al. (1997) & Woody Slash-Wind Tunnel & 8 & & $\sim 25$ & \\
\hline
\end{tabular}

${ }^{a}$ Includes the results presented in Radke et al. (1988).

$b$ "Unpublished data" presented in Ward and Hardy (1991).

${ }^{c}$ Unspecified, but likely heavily flaming phase weighted.

C burned (Ward et al., 1991; Ferek et al., 1998). Smoldering phase emission factors tend to also be lower for tropical burning.

As each data set from individual investigations also has a very large standard deviation (up to $50 \%$ of the mean value), applying simple fuel or combustion categorization does not reduce much of the variance. This variability is not because of the simple "flaming" and "smoldering" categorization, but rather the naturally chaotic and inconsistent nature of fires. Those manuscripts that published plots of particle emission factors as a function of combustion efficiency (for $\mathrm{n}>3$ ), or particle concentration as a function of $\mathrm{CO}$ or $\mathrm{CO}_{2}$ concentration, clearly demonstrate this fact. For example Radke et al. (1991), Ward et al. (1996) and Ferek et al. (1998) all show regression coefficient $\left(\mathrm{r}^{2}\right)$ values of roughly $50 \%, 56 \%$, and $25 \%$, respectively. That implies that typically less than $50 \%$ of the variance in particle emission factors is accounted for by the combustion efficiency alone.

There are further questions of sampling methods and biases, as data has been collected from such diverse methods 
as combustion chambers, sampling towers, and aircraft. Each of these has their own inherent bias: Combustion chambers cannot adequately duplicate fire size, temperature, and ventilation issues. Towers have the advantage of longer and more time integrated sampling, but may sample particles when the plume is too hot, before the particles have properly condensed into their final state (Ferek et al., 1998). Aircraft can only sample the largest plumes and must deal with lower sample numbers, concentrations and loadings, thus increasing sample and processing errors. Instrumentation methods that rely on single particle counters rather than filter measurements probably perform poorly in high concentration smoke plumes. Because there are so few measurements in the literature, it is difficult to determine the extent of each individual bias and its impact on the community data set.

The application of these methods is strongly associated with fire intensity and hence particle emission bias. Most of the North American fire data was collected through specially prepared prescribed burns or combustion chamber studies. Of the 17 fires presented by Radke et al. (1991), only 3 are wild fires. Of four fires presented by Hobbs et al. (1996) only one was a wild fire. These measurements were predominately made by aircraft sampling the fires during the most intense burning periods. Conversely, the Patterson et al. (1984, 1986) fires are from pine needles in a combustion chamber and are somewhat different from fuel in the natural environment. Certainly the lack of sampling of the continental scale wildfires (e.g., British Columbia fires of 1981-1982, Yellowstone fire of 1988, Idaho and Montana fires of 2000) may be a serious lapse in the community data set. There is a large uncertainty as to whether the planned controlled burns that make up much of the community data set can adequately describe everyday controlled burns or the extreme cases which receive most of the attention of radiative studies. Similarly, one must question the relevancy of the published $\sim 15$ fires from Amazonia that are used to characterize smoke emissions for the entire Amazon Basin. Ultimately, the question becomes whether these few samples can adequate describing the complex nature of fire particle emissions on continental scales. For example, it is well known that fires in the Amazon can smolder for days. The real contribution of this prolonged smoldering stage is mostly unknown.

\section{Discussion, summary, and recommendations for fu- ture work}

In this manuscript we gave an overview of the intensive physical and chemical properties of smoke particles from biomass burning. We focused on the commonly studied fuels such a grass/savanna, cerrado/brush forest, tropical forest and temperate forest. Although there is a tremendous body of literature on the subject of biomass-burning particles and some agreement on key issues, there are some obvious biases. Here we provide a summary and discuss the state-of-the-science.
Where appropriate, present first order models are presented. We close each section with a discussion of outstanding issues.

\subsection{Particle emission}

Examination of Table 6 shows that while emission factors for grass and cerrado/shrub fuels are relatively well known, uncertainties dramatically increase for more forested biomes. These are likely due to a combination of sampling bias, instrumentation issues, and low statistical power (e.g., sample size). Grass and shrub fires are smaller in size and intensity, and are mostly consumed by flaming combustion. These aspects make such fires easier to characterize. Forested fires pose far more difficult challenges. Clearly, the high particle concentrations and temperatures make close analytical studies of these fires difficult and potentially dangerous. Since the heat source is so much larger than grass fires, modeling the impact of fire dynamics and intensity on particle properties is complex and non-linear. Long burn times, on the order of days for smoldering combustion to complete, makes monitoring the complete lifecycle and derivation of a "mean" emission factor logistically difficult for a forest fire. Additionally, we need to account for rapid particle condensation near the fire source.

Here we present a first order model for particle emissions. Net emission fluxes are most often determined by applying emission factors to estimates of land area burned, fuel loading, carbon fraction of the fuel, and combustion fraction. Following Seiler and Crutzen (1980) to derive the total flux of species ( $\mathrm{n}$ ) by summing over each vegetation/biome type (i):

Net Flux $=\sum_{i} m_{f i} \cdot f_{c i} \cdot c_{f i} \cdot\langle E F\rangle_{n i} \cdot\left(\frac{A_{i}}{T_{i}}\right)$

where $m_{f i}$ is the amount of fuel mass available for combustion in kilograms per square meter, $f_{c i}$ is the average mass fraction of carbon in the fuel, $c_{f i}$ is the combustion factor, $A_{i}$ is the total area burned, $T_{i}$ is the average time between burns, and here $\left\langle E F>_{n i}\right.$ is the average emission factor for particles.

In Table 7 we present recommended emission factors and an uncertainty analysis of the factors required to forward model particle emissions. Because of the huge uncertainties in burn areas and fuel loads, we present data normalized as emissions per square meter burned, and assume some reasonable average fuel load for comparison purposes only from the values given above (i.e., not included in the uncertainty calculation). We recommend values for emission factors that are slightly higher than those in previous review papers that average the bulk of available emission factor data in the literature (such as Andreae and Merlet, 2003). We hypothesize that due to various sample bias issues, such an average would underestimate emissions on the order of 10 to $30 \%$. First, one must consider issues of particle mass growth due 
Table 7. Simplified biomass burning particle models. Estimates of smoke particle emissions (PM2.5) parameters based on reasonable values of key parameters and their absolute uncertainties when averaged over large numbers of fires. Under phase is given the rough fraction of the amount of combustion for flaming $(\mathrm{F})$ and smoldering $(\mathrm{S})$. For individual fires, uncertainties may be more than a factor of two higher. Carbon fraction numbers are based on Turn et al. (1997), Susott et al. (1996) and Guild et al. (1998). Combustion fraction and fuel loads are assumed to be the same for flaming and smoldering combustion, (although no verification of this assumption exists). Fuel loads are given as a lower-median-upper end values and are considered reasonable but may be highly uncertain. The mean value without uncertainty is given for illustrative purposes.

\begin{tabular}{|c|c|c|c|c|c|}
\hline & Savanna/Grass & Woody Savanna \& Cerrado & Tropical Forest/Slash & Temperate-Boreal Forest/Slash & Boreal Forest \\
\hline \multicolumn{6}{|l|}{ Emission Characteristics } \\
\hline Fuel Load $\left(\mathrm{kg} \mathrm{m}^{-2}\right)^{a}$ & $0.1-0.4-0.7$ & $0.5-2-5$ & $10-30-45$ & $7-15-40$ & $2.5-8-15$ \\
\hline Phase (Flam./Smold.) & $93 / 7 \%$ & $75 / 25 \%$ & $45 / 55 \%$ & $40 / 60 \%$ & $40 / 60 \%$ \\
\hline Carbon Fraction ${ }^{b}$ & $0.47 \pm 0.02$ & $0.50 \pm 0.02$ & $0.51 \pm 0.02$ & $0.51 \pm 0.02$ & $0.51 \pm 0.02$ \\
\hline Combustion Fraction $^{a}$ & $0.85 \pm 0.1$ & $0.6 \pm 0.1$ & $0.5 \pm 0.1$ & $0.5 \pm 0.1$ & $0.5 \pm 0.1$ \\
\hline PM2.5 EF F/S $\left(\mathrm{g} \mathrm{kg}^{-1} \mathrm{C}\right)$ & $12 \pm 2 / 30 \pm 12$ & $13 \pm 4 / 30 \pm 12$ & $17 \pm 8 / 30 \pm 15$ & $25 \pm 15 / 40 \pm 20$ & $20 \pm 12 / 40+15$ \\
\hline PM2.5 EF Avg. $\left(\mathrm{g} \mathrm{kg}^{-1} \mathrm{C}\right)$ & $14 \pm 3$ & $17 \pm 4$ & $24 \pm 9$ & $34 \pm 14$ & $32 \pm 10$ \\
\hline PM2.5 Emissions $\left(\mathrm{g} \mathrm{m}^{-2}\right)$ & $2 \pm 0.5$ & $10 \pm 4$ & $184 \pm 70$ & $204 \pm 87$ & $81 \pm 25$ \\
\hline \multicolumn{6}{|l|}{ Size (fresh/aged) } \\
\hline $\mathrm{CMD}(\mu \mathrm{m})$ & $0.11 \pm 0.01 / 0.15+0.02$ & $0.11 \pm 0.01 / 0.15 \pm 0.02$ & $0.12 \pm 0.01 / 0.19 \pm 0.03$ & $0.16 \pm 0.03 / 0.20 \pm 0.03$ & $0.13 \pm 0.01 / 0.18 \pm 0.02$ \\
\hline$\sigma_{g c}$ & $1.8 \pm 0.1 / 1.6+0.1$ & $1.8 \pm 0.1 / 1.6 \pm 0.1$ & $1.7 \pm 0.1 / 1.55 \pm 0.2$ & $1.7 \pm 0.1 / 1.55+0.2$ & $1.7 \pm 0.1 / 1.6 \pm 0.1$ \\
\hline $\operatorname{VMD}(\mu \mathrm{m})$ & $0.26 \pm 0.04 / 0.30 \pm 0.03$ & $0.26 \pm 0.04 / 0.31 \pm 0.03$ & $0.27 \pm 0.03 / 0.32 \pm 0.03$ & $0.26 \pm 0.04 / 0.34 \pm 0.03$ & $0.26 \pm 0.04 / / 0.32 \pm 0.03$ \\
\hline$\sigma_{g c}$ & $1.8+0.1 / 1.6 \pm 0.1$ & $1.8+0.1 / 1.6 \pm 0.1$ & $1.7 \pm 0.1 / 1.5 \pm 0.2$ & $1.7+0.1 / 1.5 \pm 0.2$ & $1.8+0.1 / 1.5 \pm 0.2$ \\
\hline
\end{tabular}

${ }^{a}$ Values for fuel load and combustion fraction are given as a lower, central and maximum value and are derived from the findings of Shea et al. (1996), Kaufman et al. (1995), FIRESCAN (1996), Guild et al. (1998), Hobbs et al. (1996), Ward et al. (1992).

${ }^{b}$ Values for carbon fraction of fuel are derived from the findings of Susott et al. (1996), Guild et al. (1998), and Hughes et al. (1999).

to organic condensation during the first 30 min of smoke aging (we exclude other heterogeneous mass growth such as organic acid formation as this is heavily dependent on environmental variables this should be accounted for in models). This mass increase is not accounted for in fire tower measurements, nor even in many aircraft derived values. Similarly, combustion chamber studies are also likely to underestimate some emissions for forested type fuels. This correction would be greater for flaming combustion, and can be taken into account directly in the emission factors (which we have done).

The second issue is the lack of data on the relative amounts of flaming versus smoldering combustion. Even for savanna type fires, smoldering combustion on stumps and large wood debris can go on for hours or even days (D. Ward personal communication). While the mass flux is relatively slow, the long duration may make this a term that should not be neglected. For fires in forested ecosystems, smoldering is even more significant. This correction results in another 5-15\% increase in the average emission factor.

The bulk of the uncertainty in normalized net emissions calculations still lies with the average emission factor, which we estimate to be $\sim 18 \%$ for grassy fuels (which show very consistent results in the literature), to mid values of $37 \%$ and a high of $40 \%$ for tropical forests (for which relatively few measurements are made). The higher mean uncertainties for emission factors from forest type fuels are not unexpected given the difficulty in characterizing large fires. For example, grass fires burn typically in the flaming phase and can be easily characterized by fire towers. Larger forest fires, however, have significant smoldering phases that can last for days (increasing uncertainty to that of the flaming plus smoldering phase). Large fires also vary considerably from event to event causing more spread in the community data set.

A significant step in assessing smoke particle impacts on climate is to model the relationship of data from individual fires to the evolved plumes that affect the chemistry and radiative balance of the atmosphere. This fundamental process is still largely unknown, and is a critical link between fieldwork and accurate climate models. Emission factor uncertainties are strongly tied to the estimation of net emissions (and hence burned areas) on continental scales. This, of course, leads to the problem of forward modeling the net production of smoke particles in a region. Simply making more measurements similar to those presented in Table 6 of individual emission factors are unlikely to reduce the uncertainty by much. Besides, it is widely known that the most significant reduction in uncertainty in the forward production problem is simply in the amount of area burned and fuel load, not in the emission factor. Until such extensive parameters are better defined, through a combination of better government documentation, satellite burn scar analysis, or active remote sensing fire detection, forward derivations of smoke particle emissions will remain highly uncertain. Given this state of 
the science, receptor/box modeling may be the most advantageous method currently available. Regional optical depths can now be measured fairly accurately with remote sensing systems. By combining such data with meteorological model output, transport fluxes can be estimated though a box model type of approach. But, one must be mindful that while this may circumvent the source function problem, the sometimeshigh uncertainties in particle microphysical and optical properties will introduce their own errors into the analysis.

\subsection{Particle size and chemistry of fresh particles}

In situ particle size distribution reports have for the most part remained static over the past two decades. First order particle size estimates are also presented on Table 7. Eighty percent of mass and over ninety percent of scattering can be attributed to the fine mode. The volume median diameter of the fine mode is typically in the range of 0.25 to $0.30 \mu \mathrm{m}$ for freshly generated smoke, with geometric standard deviations being on the order of 1.6 to 1.9. Aged smoke tends to be $0.03-0.08 \mu \mathrm{m}$ larger, and to have narrower geometric standard deviations $(\sim 1.4-1.6)$. There have been isolated reports from inversions of Sun / sky photometer data, however, of considerably larger haze particles (volume median diameters on the order of $0.4-0.5 \mu \mathrm{m}$ ) resulting from peat fires in areas such as western Russia and Southeast Asia. It is unclear whether this is due to larger primary particles from extreme smoldering combustion, or to the increased production of hygroscopic species, such as sulfates (gas-to-particle conversion of $\mathrm{SO}_{2}$ ), coupled with high humidity that results in formation of large haze particles. As peat fires are increasingly recognized as a major source of smoke particles (e.g., Page et al., 2002), this issue requires further study.

Smoke particles are usually internally mixed, typically with a core of black carbon and alkali earth compounds (such as potassium chloride) coated with organic compounds. Smoldering combustion creates spherical particles with smaller or absent refractory cores. Black carbon typically accounts for $4-8 \%$ smoke particle dry mass, followed by a highly variable $\sim 5-15 \%$ from various inorganic species. Approximately $50-65 \%$ of mass is attributable to organic carbon, and 70 to $85 \%$ to organic species. Hydrocarbons are predominately long chain n-alkanes, with carbohydrates ( $\sim 10-20 \%$ total mass), organic acids $(5-20 \%)$ and various alcohols, phenols, and aldehydes. As a mass fraction, aging smoke has considerably lower concentrations of tracer species such as black carbon and potassium, and is significantly enriched in secondary products such as sulfate, organic acids, and "semi-volatile" organic species.

Unlike particle emission factors and size, we are hesitant to suggest a smoke chemistry model (other than the generalities discussed above). Comparisons of data sets in the literature are difficult. Many studies perform only limited analysis on selected samples. For example, isolated ion chromatography results are difficult to compare to studies of particle properties using a GC/MS. To date, in the literature there have been few complete and comparable set of measurements that would allow the total chemical composition to be assessed. Second, fundamental gravimetric analyses are often neglected in particle chemistry studies. This significantly hampers interpretation and comparison of results. Third and most importantly, while the findings from individual reports of black and organic carbon content can be argued on physical grounds, the fact is that artifact is significant. The high mass fraction of ill-defined semi-volatile organic compounds in smoke may complicate matters, and is only just beginning to be addressed in the literature. The uncertainties in BC estimates, and in particular the recent findings of Mayol-Bracero et al. (2002) that much of what is analyzed as BC may in fact be $\mathrm{OC}$, is extremely disturbing. Conversely, negative biases have also been suggested.

The greatest need for smoke particle chemistry research is a true quantification method for organic carbon, black carbon, and the ratio of particulate organic matter to organic carbon. Clearly, advancements beyond thermal methods are desperately required. At the very least, multiple filter methods (such as Novakov et al., 1997 and Turpin et al., 2000) with proper gravimetry need to be adopted as standard protocols for smoke particle research. Additional reports of black to organic carbon ratios without proper gravimetric analysis, and without mass closure with inorganic species, are of limited use to the scientific community. Until the BC/OC/POM issue is resolved, absorption and scattering studies from calculations based on measurements may need to be considered subjective or academic.

\subsection{Particle evolution}

It is evident from a multitude of studies that the physical and chemical properties of smoke particles rapidly change with age, with regional hazes typically having volume median diameters $\sim 0.05 \mu \mathrm{m}$ larger than fresh smoke. This can cause a disjoint between primary measurements near source regions and the continental scale plumes that are of most interest to the climate community. Particle growth has been observed on many time scales, and differences exist between surface and airborne measurements. While this in part may be due to instrumentation differences, it is highly likely that smoke particles can change in the first minutes after emission. Some studies have shown growth rates in the volume median diameter in excess of $0.04 \mu \mathrm{m}$ per hour.

Historically, coagulation is the only growth mechanism considered for smoke transport modeling. It is likely that other significant processes occur on time scales ranging from minutes to days. Condensation of primary organic gases, gas to particle conversion of inorganic and organic species such as sulfates and organic acids, and cloud processing all have a role. We must also consider that smoke is often mixed with other anthropogenic emissions. Such mixing increases the complexity of the "photochemical soup" that currently exists 
in aged smoke plumes, and hence amplifies uncertainties in modeling or remote sensing studies.

A more thorough study is required to determine exactly what these processes are, and on what time scales they are important. In particular, we need a much better understanding of the physical processes which act on smoke particles in the first several minutes after emission. This may help reduce sampling bias and uncertainty in the emission factors. On the other end of the scale, chemistry and particle transport models should help reduce uncertainties on particle fate. Continental sized smoke plumes can only be dispersed on scales equal to their own scale. Hence, understanding meso and synoptic scale transport mechanisms should be a high priority.

In addition to the physical processes causing differences in particle size during aging, the community must consider that in most field studies there is a high likelihood of sampling bias. Consider the variability in particle properties displayed in the earlier sections of this manuscript. With such inherent variability in smoke, and with sampling errors, it is very unlikely that smoke in a regional haze can be easily compared to individual study fires with very specific properties. Wind tunnels have difficulty matching natural fire properties. Surface based and tower studies are labor intensive, and consequently only a few fires have been studied. Airborne studies, while having the advantage of sampling many fires, are often limited to only the largest plumes. To our knowledge, there has yet to be a study that can quantitatively account for all of the source characteristics of the ensemble of burning activity in a region. There have been some attempts at Lagrangian sampling of large individual fires in temperate forests (e.g., Radke et al., 1995; Hobbs et al., 1996), but they are few in number, and are susceptible to large uncertainties in the trajectory analysis. As fires evolve rapidly, how sure can one be that the smoke properties measured at the source are identical to those of the parcel being measured several hours to days downwind? Hence any discussion of plume evolution can currently only be semi-quantitative.

Recent advances in modeling techniques, however, are finally making the simulation of the smoke aging process at high resolution possible. Despite the complexity of the chemical properties of an evolving smoke plume, as well as our limited ability to characterize such plumes with regards to chemical constituents or reactions, such research is extremely important to our future understanding of the aging process. Early attempts of such work, such as Trentmann et al. (2002) for a prescribed temperate fire or Jost et al. (2003) for grass fires yield promising results. By specific modelobservation comparisons such work can constrain the physical model and allow for a more reliable scale analysis of relevant evolutionary processes-particularly with regards to secondary production and condensation. A host of fire parameters relating to emissions and diffusion can be checked for consistency and the effect of non-linear process can be examined in detail. Future field campaigns would benefit greatly from fundamental involvement of mesoscale chemistry models during the mission-planning phase, and emphasize targeted observations to support such work. Even retrospective studies of available cases should be considered a high priority for the scientific community. When such studies of individual plumes close with the regional receptor analyses a complete physical picture of burning can finally be formed.

\subsection{Particle thermodynamics}

Biomass-burning particles have long been known to be effective $\mathrm{CCN}$, and hence to have a significant influence on cloud microphysics and, in some cases, precipitation processes. A reciprocal issue is the impact of cloud haze droplet on particle heterogeneous chemistry and evolution. In regions with significant moisture (such as Amazonia) and cumulus coverage, ternary nucleation and cloud processing may be an important (and as of yet mostly unexplored) part of the particle aging process. The presence of organic acids, in addition to inorganic species such as sulfate and potassium chloride, provides more than enough solubility for smoke particles to activate cloud droplets. Consequently, observations of significant decreases in cloud droplet size and of increased reflectivity due to smoke particle activation are commonly reported (e.g., Hudson et al., 1991; Kaufman and Fraser, 1997; Reid et al., 1999b; Breon and Colzy, 2000), and precipitation effects are currently under study (Rosenfeld, 1999).

Outstanding questions include the degree to which particle $\mathrm{CCN}$ efficiencies and concentrations must be known before the indirect effects can be adequately modeled in large-scale simulations. An outstanding issue facing indirect forcing/precipitation studies is still determining the relationship between particle size and chemistry (affecting CCN efficiency) and cloud dynamics/microphysics. It is known that for convective clouds with moderate to high supersaturations $(>0.5 \%)$, smoke particle size and chemistry become second order to simple concentration. Consider that biomass burning particles are very weakly soluble (this is well demonstrated by their low hygroscopicity), and sulfates are highly soluble (as is demonstrated by their high hygroscopicity). Using a CCN remover Ji et al. (1998) and Ji (personal communication) reported that at supersaturations above $0.5 \%$, smoke particles in Brazil have nearly the same $\mathrm{CCN}$ spectrum as sulfate aerosols measured off of the east coast of the United States. This result is consistent with the findings that the effective radius $\left(r_{e f f}\right)$ - liquid water content (LWC) relationship for clouds in TARFOX (east coast of the US) is nearly the same as that for clouds in Brazil (Reid et al., 1999b). Since sulfates and biomass-burning particles have quite different compositions, these observations suggest that chemical composition may be secondary in determining CCN activities, and the $r_{\text {eff }}$ - LWC relationship for convective clouds. This is in part likely due to the sheer number of available particles in regions impacted by biomass 
smoke. Consider that the number mode of smoke particles is in the range of 0.1 to $0.2 \mu \mathrm{m}$ - large enough by size alone for wetable non-soluble particles to nucleate cloud droplets at $1 \%$ supersaturation. There is always a large enough particle to form a cloud droplet, and convective clouds tend to have relatively high peak supersaturations where almost any particle can be a CCN.

Stratiform clouds (e.g., stratocumulus), however, are more sensitive to $\mathrm{CCN}$ chemical properties. In these cases, maximum supersaturations are low, and particle CCN efficiency becomes dominant; only the most soluble will activate. Reid et al. (1999b) observed a much stronger dependence of particle concentration on $r_{e f f}-$ LWC for stratiform clouds. A reconsideration of the cloud reflectivity estimates from Kaufman and Fraser (1997) suggests a potential bias towards stratiform clouds in their analysis, hence highlighting the indirect effect. Thus, the $\mathrm{CCN}$ properties of smoke may be best explored in regions with stratoform clouds as the natural laboratory.

Acknowledgements. We are grateful the Office of Naval Research Code 322 and the NASA EOS Interdisciplinary Science Program (EOS/IDS) for supporting this work. Additional assistance was provided by the German American Academic Council (GAAC). We are most grateful to T. Bond and D. Hegg of the University of Washington for their helpful comments.

Edited by: A. Petzold

\section{References}

Abel, S., Haywood, J. M., Highwood, E. J., Li, J., and Buseck, P. R.: Evolution of biomass burning aerosol properties from an agricultural fire in south Africa, Geophys. Res. Lett., 30, 15, 1783, doi:10.1029/2003GL017342, 2003.

Anderson, B. E., Grant, W. B., Gregory, G. L., Browell, E. V., Collins Jr., J. E., Sachse, D. W., Bagwell, D. R., Hudgins, C. H., Blake, D. R., and Blake, N. J.: Aerosols from biomass burning over the tropical South Atlantic region: Distributions and impacts, J. Geophys. Res., 101, 24 117-24 137, 1996.

Andreae, M. O.: Biomass burning: its history, use, and distribution and its impact on environmental quality and global climate, in: Global Biomass Burning: Atmospheric, Climactic and Biospheric Implications, edited by: Levine, J. S., pp. 3-21, MIT Press, New York, 1991.

Andreae, M. O., Andreae, T. W., Annegarn, H., Beer, J., Cachier, H., Le Canut, P., Elbert, W., Maenhaut, W., Salma, I., Wienhold, F. G., and Zenker, T.: Airborne studies of aerosol emissions from savanna fires in southern Africa: 2. Aerosol chemical composition, J. Geophys. Res., 103, 32 119-32 128, 1998.

Andreae, M. O., Atlas, E. , Cachier, H., Cofer III, W. R., Harris, G. W., Helas, G., Koppmann, R., Lacaux, J. P., and Ward, D. E.: Trace gas and aerosol emissions from savanna fires, in: Biomass Burning and Global Change, Vol. 1, edited by: Levine, J. S., pp. 278-295, MIT Press, New York, 1996.

Andreae, M. O., Browell, E. V., Garstang, M., Gregory, G. L., Harriss, R. C., Hill, G. F. , Jacob, D. J., Pereira, M. C., Sachse, G. W.,
Setzer, A. W., Silvia Dias, P. L., Talbot, R. W., Torres, A. L., and Wolfsy, S. C.: Biomass burning emissions and associated haze layers over Amazonia, J. Geophys. Res., 93, 1509-1527, 1988.

Andreae, M. O. and Merlet, P.: Emission of trace gases and aerosols from biomass burning, Glob. Biogeochem. Cycles, 15, 955-966, 2003.

Appel, B. R., Cheng, W., and Salaymeh, F.: Sampling of carbonaceous particles in the atmosphere-II, Atmos. Environ., 23, 2167$2175,1989$.

Appel, B. R., Tokiwa, Y., and Kothny, E. L.: Sampling of carbonaceous particles in the atmosphere, Atmos. Environ., 17, 17871769, 1983.

Artaxo, P., Fernandes, E. T., Martins, J. V., Yamasoe, M. A., Hobbs, P. V., Maenhaut, W., Longo, K. M., and Castanho, A.: Largescale aerosol source apportionment in Amazonia, J. Geophys. Res., 103, 31 837-31 847, 1998.

Artaxo, P., Gerab, F., Yamasoe, M. A., and Martins, J. V.: Fine mode aerosol composition at three long-term atmospheric monitoring sites in the Amazon Basin, J. Geophys. Res., 99, $22857-$ $22868,1994$.

Artaxo, P., Storms, H., Bruyneseels, F., Van Grieken, R., and Maenhaut, W.: Composition and sources of aerosols from the Amazon Basin, J. Geophys. Res., 93, 1605-1615, 1988.

Babbitt, R. E., Ward, D. E., Susott, R. S., Artaxo, P., and Kauffman, J. B.: A comparison of concurrent airborne and ground based emissions generated from biomass burning in the Amazon Basin, in: SCAR-B Proceedings, edited by: Kirchhoff, V., pp. 23-26, Transtec Editorial, Sao José dos Campos, Brazil, 1997.

Bohren, C. F.: Clouds in a Glass of Beer, John Wiley \& Sons, New York, 1987.

Breon, F. M. and Colzy, S.: Global distribution of cloud droplet effective radius from POLDER polarization measurements, Geophys. Res. Lett., 27, 4065-4068, 2000.

Cachier, H., Bremond, M. P., and Buat-Menard, B.: Determination of atmospheric soot carbon with a simple thermal method, Tellus, 41B, 379-390, 1989.

Cachier, H., Ducret, J., Bremond, M. P., Yoboue, V., Lacaux, J. P., Gaudichet, A., and Baudet, J., Biomass Burning in a Savannah Region of the Ivory Coast, in: Global Biomass Burning: Atmospheric, Climactic and Biospheric Implications, edited by: Levine, J. S., pp. 174-180, MIT Press, New York, 1991.

Cachier, H., Liousse, C., Buatmenard, P., and Gaudichet, A.: Particulate content of savanna fire emissions, J. Atmos. Chem., 22, 123-148, 1995.

Cachier, H., Liousse, C., Pertuisot, M. H., Gaudichet, A., Echalar, F., and Lacaux, J. P.: African fire particulate emissions and atmospheric influence, in: Biomass Burning and Global Change, Vol. 1, edited by: Levine, J. S., pp. 428-440, MIT Press, New York, 1996.

Cadle, S. H., Groblicki, P. J., and Mulawa, P. A.: Problems in the sampling and analysis of carbon particulate, Atmos. Environ., 17, 593-600, 1983.

Cadle, S. H., Groblicki, P. J., and Stroup, D. P.: Automated carbon analyzer for particulate samples, Anal. Chem., 52, 2201-2206, 1980.

Calloway, C. P., Li, S., Buchanan, J. W., and Stevens, R. K.: A refinement of the potassium tracer method for residential wood smoke, Atmos. Environ., 23, 67-69, 1989.

Campbell, D., Copeland, S., and Cahill, T. A.: Response to "Com- 
ment on Measurement of aerosol absorption coefficient from Teflon filters using the integrating plate and integrating sphere techniques", Aerosol Sci. Tech., 24, 225-229, 1996.

Chandler, C., Cheney, P., Thomas, P., Trabaud, L., and Williams, D.: Fire in Forestry, Vol. 1, Wiley, New York, 1983.

Chow, J. C., Watson, J. G., Crow, S., Lowenthal, D. H., and Merrifield, T.: Comparison of IMPROVE and NIOSH carbon measurements, Aerosol Sci. Tech., 34, 23-34, 2001.

Chow, J. C., Watson, J. G., Pritchett, L. C., Pierson, W. R., Frazier, C. A., and Purcell, R. G.: The DRI thermal/optical analysis system: Description, evaluation and applications in U.S. air quality studies, Atmos. Environ., 27A, 1185-1201, 1993.

Cofer III, W. R., Levin, J. S., Sebacher, D. I., Winstead, E. L., Riggan, P. J., Stocks, B. J., Brass, J. A., Ambrosia, V. G., and Boston, P. J.: Trace gas emissions from chaparral and boreal forest fires, J. Geophys. Res., 94, 2255-2259, 1989.

Cofer III, W. R., Winstead, E. L., Stocks, B. J., Overbay, L. W., Goldammer, J. G., Cahoon, D. R., and Levine, J. S.: Emissions from boreal forest fires: are the atmospheric impacts underestimated?, in: Global Biomass Burning and Global Change, edited by: Levine, J. S., MIT Press, Cambridge, Mass, pp 716-732, 1996.

Collins, D. R., Flagan, R. C., and Seinfeld, J. H.: Improved inversion of scanning DMA data, Aerosol Sci. Technol., 36(1), 1-9, 2002.

Dasch, J. M.: Particulate and gaseous emissions from wood burning fireplaces, Environ. Sci. Tech., 16, 639-645, 1982.

Delany, A. C., Haagensen, P., Walters, S., and Wartburg, A. F.: Photochemically produced ozone in the emissions from large-scale tropical vegetation fires, J. Geophys. Res., 90, 2425-2429, 1985.

Delumea, R., Chu, A. F., and Macias, E.: Determination of elemental carbon component of soot in ambient aerosol samples, Atmos. Environ., 14, 647-652, 1980.

de Zarate, I. O., Ezcurra, A., Lacaux J. P., and Van Dinh P.: Emission factor estimates of cereal waste burning in Spain, Atmos. Environ., 34, 3183-3193, 2000.

Dinh, P. V., Lacaux, J. P., and Serpolay, R.: Cloud forming properties of biomass burning aerosols, in: Nucleation and Atmospheric Aerosols, edited by: Fukuta, N. and Wagner, P. E., pp. 173-176, Deepak Publishing, New York, 1992.

Dubovik, O., Holben, B. N. , Eck, T. F., Smirnov, A., Kaufman, Y. J., King, M. D., Tanre, D., and Slutsker, I.: Variability of absorption and optical properties of key aerosol types observed in worldwide locations, J. Atmos. Sci., 59, 590-608, 2002.

Eagan, R. C., Hobbs, P. V., and Radke, L. F.: Measurements of cloud condensation nuclei and cloud droplet size distributions in the vicinity of forest fires, J. Appl. Meteor., 13, 553-557, 1974.

Eatough, D. J., Eatough, N. L. , Pang, Y., Sizemore, S., Kirchstetter, T. W., Novakov, T., and Hobbs, P. V.: Semi volatile particulate organic material in southern Africa during SAFARI 2000, J. Geophys. Res., 108(D13), 8479, doi:10.1029/2002JD002296, 2003.

Echalar, F., Artaxo, P., Martins, J. V., Yamasoe, M., and Gerab, F.: Long-term monitoring of atmospheric aerosols in the Amazon Basin: Source identification and apportionment, J. Geophys. Res, 103, 31 849-31 864, 1998.

Eck, T. F., Holben, B. N., Reid, J. S., O’Neill, N. T., Schafer, J. S., Dubovik, O., Smirnov, A., and Yamasoe, M. A.: High aerosol optical depth biomass burning events: a comparison of opti- cal properties for different source regions, Geophys. Res. Lett., 30(24), 2293, doi:10.1029/2003GL018697, 2003.

Einfeld, W., Ward, D. E., and Hardy, C. C.: Effects of fire behavior on prescribed fire smoke characteristics: A case study, in: Global Biomass Burning: Atmospheric, Climatic, and Biospheric Implications, edited by: Levine, J. S., pp. 412-3419, MIT Press, Cambridge, Mass, 1991.

Elias, V. O., Simoneit, B. R. T. , Periera, A. S., Cabral, J. A., and Cardoso, J. N.: Detection of high molecular weight organic tracers in vegetation smoke by high-temperature gas chromatography-mass spectroscopy, Environ. Sci. Technol., 33, 2369-2376, 1999.

Fang, M., Zheng, M., Wang, F., To, K. L., Jaafar, A. B., and Tong, S. L.: The solvent-extractable organic compounds in the Indonesia biomass burning aerosols-characterization studies, Atmos. Environ., 33, 783-795, 1999.

Fearnside, P. M.: Fire in the tropical rain forest of the Amazon Basin, in: Fire in the Tropical Biota (Ecological Studies 84), edited by: Goldammer, J. G., pp. 106-115, Springer-Verlag, New York, 1990.

Feingold, G., Remer, L. A., Ramaprasad, J., and Kaufman, Y. J.: Analysis of smoke impact on clouds in Brazilian biomass burning regions: An extension of Twomey's approach, J. Geophys. Res., 106, 22 907-22 922, 2001.

Ferek, R. J., Reid, J. S., Hobbs, P. V., Blake, D. R., and Liousse, C.: Emission factors of hydrocarbons, trace gases and particles from biomass burning in Brazil, J. Geophys. Res., 103, 32 107-32 118, 1998.

Fiebig, M., Stohl, A., Wendisch, M., Eckhardt, S., and Petzold, A.: Dependence of solar radiative forcing of forest fire aerosol on aging and state of mixture, Atmos. Chem. Phys., 3, 881-891, 2003,

SRef-ID: 1680-7324/acp/2003-3-881.

FIRESCAN Science Team: Fire in Ecosystem of Boreal Eurasia: The Bor Forest Island Fire Experiment Fire Research Campaign Asia-North (FIRESCAN), in: Biomass Burning and Global Change, Vol. 1, edited by: Levine, J. S., pp. 848-873, MIT Press, New York, 1996.

Finlayson-Pitts, B. J. and Pitts, J. N.: Atmospheric Chemistry: Fundamentals and Experimental Techniques, John Wiley, New York, 1986.

Formenti, P., Elbert, W., Maenhaut, W., Haywood, J., Osborne, S., and Andreae, M. O.: Inorganic and carbonaceous aerosols during the Southern African Regional Science Initiative (SAFARI 2000) experiment: Chemical characteristics, physical properties, and emission data for smoke from African biomass burning, J. Geophys. Res., 108(D13), 8488, doi:10.1029/2002JD002408, 2003.

Formenti, P., Reiner, T., Sprung, D., Andreae, M. O., Wendisch, M., Wex, H., Kindred, D., Dewey, K., Kent, J., Tzortziou, M., Vasaras, A., and Zerefos, C.: STAAARTE-MED 1998 summer airborne measurements over the Aegean Sea: 2. Aerosol scattering and absorption, and radiative calculations, J. Geophys. Res., 107, doi:10.1029/2001JD001536, 2002.

Forstner, J. L., Flagan, R. C., and Seinfeld, J. H.: Secondary organic aerosol from the photo oxidation of aromatic hydrocarbons: molecular composition, Environ. Sci. Tech., 31, 13451358, 1997.

Fraser M. P. and Lakshmanan, K.: Using levoglucosan as a molecular marker for the long-range transport of biomass combustion 
aerosols, Environ. Sci. Technol., 34, 4560-4564, 2000.

Fraser, R. S. and Kauffman, Y. J.: The relative importance of aerosol scattering and absorption in remote sensing, IEEE Trans. Geosci. Remote Sens., 23, 625-633, 1985.

Frenklach M.: Reaction mechanism of soot formation in flames, Phys. Chem. Chem. Phys, 4, 2028-2037, 2002.

Gao, S., Hegg, D. A., Hobbs, P. V., Kirchstetter, T. W., Magi, B. I., and Sadilek, M.: Water-soluble organic components in aerosols associated with savanna fires in southern Africa: identification, evolution, and distribution, J. Geophys. Res., 108(D13), 8491, doi:10.1029/2002JD002324, 2003a.

Gao, S., Hegg, D. A., Covert, D. S., and Jonsson, H.: Aerosol chemistry, and light-scattering and hygroscopicity during outflow from East Asia, J. Atmos. Chem., 46, 55-88, 2003b.

Gaudichet, A., Echalar, F., Chatenet, B., Quisefit, J. P., Malingre, G., Cachier, H., Buat-Menard, P., and Maenhaut, W.: Trace Elements in Tropical African Savanna Biomass Burning Aerosols, J. Atmos. Chem., 22, 19-39, 1995.

Glassman, I.: Combustion, p. 275, Academic Press, New York, 1977.

Glassman, I.: Soot formation in combustion processes, in TwentySecond Symposium (International) on Combustion, The Combustion Institute, Pittsburgh, p. 295, 1988.

Goos, A. W.: The thermal decomposition of wood, in: Wood Chemistry, edited by: Wise, L. E. and Jahn, E. L., Reinhold, New York, pp. 817-851, 1952.

Graham, B., Mayol-Bracero, O. L., Guyon, P., et al.: Water soluble organic compounds in biomass burning aerosols over Amazonia 1. Characterization by NMR and GC-MS, J. Geophys. Res., 107, doi:10.1029/2001JD000336, 2002.

Guild, L. S., Kauffman, J. B. , Ellingson, L. J., Cummings, D. L., Castro, E. A., Babbitt, R. E., and Ward, D. E.: Dynamics associated with total aboveground biomass, C, nutrient pools, and biomass burning of primary forest and pasture in Rondonia, Brazil during SCAR-B, J. Geophys. Res., 24, 32 091-32 100, 1998.

Hallett, J., Hudson, J. G., and Rogers, C. F.: Characterization of combustion aerosols for haze and cloud formation, Aerosol Sci. Technol., 10, 70-83, 1989.

Hartmann, W. R., Andreae, M. O., and Helas, G.: Measurements of organic acids over Central Germany, Atmos. Environ., 23, 1531$1533,1989$.

Hawthorne, S. B., Krieger, M. S., Miller, D. J., and Mathiason, M. B.: Collection and quantification of methooxylated phenol tracers for atmospheric pollution from residential woodstoves, Environ. Sci. Technol., 22, 470-475, 1989.

Haywood, J. M., Osborne, S. R., Francis, P. N., Keil, A., Formenti, P., Andreae, M. O., and Kaye, P. H.: The mean physical and optical properties of regional haze dominated by biomass burning aerosol measured from the C-130 aircraft during SAFARI 2000, J. Geophys. Res., 108, doi:10.1029/2002JD002226, 2003.

Hegg, D. A., Radke, L. F., and Hobbs, P. V.: Ammonia emissions from biomass burning, Geophys. Res. Lett., 15, 335-337, 1988.

Helas, G., Bingemer, H., and Andreae, M. O.: Organic acids over equatorial Africa: results from DECAFE 88, J. Geophys. Res., 97, 6187-6193, 1992.

Hinds, W. C.: Aerosol Technology: Properties Behavior and Measurement of Airborne Particles, Wiley-Interscience Publications, 1982.
Hobbs, P. V., Sinha, P., Yokelson, R. J., et al.: Evolution of gases and particles from a savanna fire in South Africa, J. Geophys. Res., 108(D13), 8485, doi:10.1029/2002JD002352, 2003.

Hobbs, P. V., Reid, J. S., Herring, J. A. , Nance, J. D., Weiss, R. E., Ross, J. L., Hegg, D. A., Ottmar, R. D., and Liousse, C.: Particle and trace-gas measurements in smoke from prescribed burns of forest products in the Pacific Northwest, in: Biomass Burning and Global Change, Vol. 1, edited by: Levine, J. S., pp. $697-$ 715, MIT Press, New York, 1006, 1996.

Hobbs, P. V. and Radke, L. F.: Cloud condensation nuclei from a simulated forest fire, Science, 163, 279-280, 1969.

Holben, B. N., Eck T. F., Setzer A., et al.: Temporal and spatial variability of aerosol loading and properties during the Amazon, North American temperate, and boreal forest burning seasons, Biomass Burning and Global Change, Vol. 2, edited by: Levine, J. S., 618-636, MIT Press, New York, 1996a.

Hornig, J. F., Soderberg, R. H., Barefoot, A. C., and Galasyn, J. F.: Wood smoke analysis: Vaporization losses of PAH from filters and levoglucosan as a distinctive marker for wood smoke, in: Polycyclic Aromatic Hydrocarbons: Mechanisms, Methods, and Metabolism, edited by: Cooke, M. and Dennis, A. J., 561-568, Battell, Columbus Ohio, 1985.

Hudson, J. G., Hallett, J., and Rogers, C. F.: Field and laboratory measurements of cloud-forming properties of combustion aerosols, J. Geophys. Res., 96, 10 847-10 859, 1991.

Hughes, R. F., Kauffman, J. B., and Jaramillo, V. J.: Biomass, carbon, and nutrient dynamics of secondary forests in a humid tropical region of Mexico, Ecology, 80, 1892-1907, 1999.

Intergovernmental Panel on Climate Change (IPCC), Climate Change 1994: Radiative Forcing of Climate Change, edited by: Houghton, J. T., Meira Filho, L. G., Bruce, J., et al., Cambridge Univ. Press, Cambridge, 1995.

Intergovernmental Panel on Climate Change (IPCC): Climate Change 2001: Radiative Forcing of Climate Change, edited by: Houghton, J. T., Ding, Y., Griggs, D. J., Noguer, M., van der Linden, P. J., and Xiaosu, D., Cambridge Univ. Press, Cambridge, 2001.

Jacobson, M. C., Hansson, H. C., Noone, K. J., and Charlson, R. J.: Organic atmospheric aerosols: Review and state of the science, Rev. Geophys., 38, 267-294, 2000.

Jenkins, B. M., Turns, S. Q., Williams, R. B., Chang, D. P., Raabe, O. G., Paskin, J., and Teague, S.: Quantitative assessment of gaseous and condensed phase emissions from open burning of biomass in a combustion wind tunnel, in: Global Biomass Burning: Atmospheric, Climatic, and Biospheric Implications, edited by: Levine, J. S., pp. 305-314, MIT Press, Cambridge, Mass, 1991.

Ji, Q., Shaw, G. E., and Cantrell, W.: A new instrument for measuring cloud condensation nuclei: Cloud condensation nucleus "remover," J. Geophys. Res., 103, 28 013-28 019, 1998.

Johnson, R. L., Shah, J. J., Cary, R. A., and Huntziker, J. J.: An automated thermo-optical method for the analysis of carbonaceous aerosol, in: Atmospheric Aerosol: Source/Air Quality Relationships, edited by: Marcias, E. S. and Hopke, P. K., ACS Symposium series No. $167 \mathrm{~m}, 1981$

Jost, C., Trentmann, J., Sprung, D., Andreae, M. O., McQuaid, J. B., and Barjat, H.: Trace gas chemistry in a young biomass burning plume over Namibia: Observations and model simulations. J. Geophys. Res., 108, 8482, doi:10.1029/2002JD002431, 2003. 
Kamens, R. M., Guo, Z., Fulcher, J. N., and Bell, D. A.: Influence of humidity, sunlight, and temperature on the daytime decay of polyaromatic hydrocarbons in atmospheric soot particles, Environ. Sci. Technol., 22, 103-108, 1988.

Kauffman, J. B., Cummings, D. L., Ward, D. E., and Babbitt, R.: Fire in the Brazilian Amazon: Biomass, nutrient pools, and losses in slashed primary forest, Oecologia, 104, 397-408, 1995.

Kauffman, J. B., Cummings, D. L., and Ward, D. E.: Fire in the Brazilian Amazon, 2: Biomass, nutrient pools, and losses in cattle pastures, Oecologia, 113, 415-427, 1998.

Kaufman, Y. J. and Fraser, R. S.: The effect of smoke particles on clouds and climate forcing, Science, 277, 1636-1639, 1997.

Kent, J. H.: A quantitative relationship between soot yield and smoke point measurements, Combustion and Flame, 63, 349358, 1986.

Kirchstetter, T. W., Novakov, T., Hobbs, P. V., and Magi, B.: Airborne measurements of carbonaceous aerosols in southern Africa during the dry biomass burning season, J. Geophys. Res., 108, doi:10.1029/2002JD002171, 2003.

Koppmann, R., Khedim, A., Rudolph, A. J., Poppe, J. D., Andreae, M. O., Helas, G., Welling, M., and Zenker, T.: Emissions of organic trace gases from savanna fires in southern Africa during the 1992 Southern African Fire Atmosphere Research Initiative and their impact on the formation of tropospheric ozone, J. Geophys. Res., 102, 18 879-18 888, 1997.

Kotchenruther, R., and Hobbs, P. V.: Humidification factors of aerosols from biomass burning in Brazil, J. Geophys. Res., 103, 32 081-32 090, 1998.

Kreidenweis, S. M., Remer, L. A., Bruintjes, R., and Dubovik, O.: Smoke aerosol from biomass burning in Mexico: Hygroscopic smoke model, J. Geophys. Res., 106, 4831-4844, 2001.

Laaksonen, A., Korhonen, P., Kulmala, M., and Charlson, R. J.: Modification of the Köhler equation to include soluble trace gases and slightly soluble substances, J. Atmos. Sci., 55, 853862, 1998.

Langmann, B. and Graff, H.: Indonesian smoke aerosols from peat fires and the contribution from volcanic sulfur emissions, Geophys. Res. Lett., 30(11), Art. No. 1547, 2003.

Le Canut, P., Andreae, M. O., Harriss, G. W., Weinhold, F. G., and Zenker, T.: Airborne studies of emissions from savanna fires in southern Africa, 1, Aerosol emissions measured with a laser optical particle counter, J. Geophys. Res., 101, 23 615-23 630, 1996.

Lee, L. W. and Chen, C.: Coagulation rate of polydisperse particles, Aerosol Sci. Tech., 3, 327-334, 1984.

Levin, Z., Ganor, E., and Gladstein, V.: The effects of desert particles coated with sulfate on rain formation in the eastern Mediterranean, J. Appl. Meteor., 35, 1511-1523, 1996.

Lewtas, J., Pang, Y., Booth, D., Reimer, S., Eatough, D. J., and Gundel, L. A.: Comparison of sampling methods for semi-volatile organic carbon associated with PM2.5, Aerosol Sci. Tech., 34, 9-22, 2001.

Li, J., Posfai, M., Hobbs, P. V., and Buseck, P. R.: Individual aerosol particles from biomass burning in southern Africa: 2. Composition and aging of inorganic particles, J. Geophys. Res., 108(D13), 8448, doi:10.1029/2002JD002310, 2003.

Lin., C., Baker, M., Charlson, R.: Absorption coefficient of atmospheric aerosols: A method for measurement, Appl. Opt., 12, 1356-1363, 1973.

Liousse, C. H., Cachier, H., and Jennings, S. G.: Optical and ther- mal measurement of black carbon aerosol content in different environments: variation of the specific attenuation cross-section sigma, Atmos. Environ., 27, 1203-1211, 1993.

Liousse, C., Devaux, C., Dulac, F., and Cachier, H.: Aging of savannah biomass burning aerosols: Consequences on their optical properties, J. Atmos. Chem., 22, 1-17, 1995.

Lobert, J. M., Scharffe, D. H., Hao, W.-M., Kuhlbusch, T. A., Seuwen, R., Warneck, P., and Crutzen, P. J.: Experimental evaluation of biomass burning emissions: Nitrogen and carbon containing compounds, in: Global Biomass Burning: Atmospheric, Climatic, and Biospheric Implications, edited by: Levine, J. S., pp. 289-304, MIT Press, Cambridge, Mass, 1991.

Lobert, J. M. and Warnatz, J.: Emissions from the combustion process in vegetation, in: Fire in the Environment: The Ecological, Atmospheric and Climatic Importance of Vegetation Fires, edited by: Crutzen, P. J. and Goldammer, J. G., John Wiley, New York, pp. 15-37, 1996.

Lohmann, U. and Lesins, G.: Stronger constraints on the anthropogenic indirect aerosol effect, Science, 298, 1012-1015, 2002.

Madronich, S., Chatfield, R. B., Calvert, J. G., Moortgat, G. K., Veyret, B., and Lesclaux, R.: A photochemical origin of acetic acid in the troposphere, Geophys. Res. Lett., 17, 2361-2364, 1990.

Magi, B. I. and Hobbs, P. V.: Effects of humidity on aerosols in southern Africa during the biomass burning season, J. Geophys. Res., 108(D13), 8495, doi:10.1029/2002JD002144, 2003.

Maenhaut, W., Salma, I., Cafmeyer, J., Annegarn, H. J, and Andreae, M. O.: Regional atmospheric aerosol composition and sources in the eastern Transvaal, South Africa, and impact of biomass burning, J. Geophys. Res., 101, 19, 23 631-23650, 1996.

Martins, J. V., Artaxo., P., Hobbs, P. V., Liousse, C., Cachier, H., Kaufman, Y. J., and Plana-Fattori, A.: Particle size distributions, elemental compositions, carbon measurements, and optical properties of smoke from biomass burning in the Pacific Northwest of the United States, in: Global Biomass Burning and Global Change, edited by: Levine, J. S., pp. 716-732, MIT Press, Cambridge, Mass, 1996.

Martins, J. V., Artaxo, P., Liousse, C., Reid, J. S., Hobbs, P. V., and Kaufman, Y. J.: Effects of black carbon content, particle size, and mixing on light absorption by aerosols from biomass burning in Brazil, J. Geophys. Res., 103, 32 041-32 050, 1998a.

Martins, J. V., Hobbs, P. V., Weiss, R. E., and Artaxo., P.: Sphericity and morphology of smoke particles from biomass burning in Brazil, J. Geophys. Res., 103, 32 051-32 058, 1998 b.

Mayol-Bracero, O. L., Graham, B., Guyon, P., Andreae, M. O., Decesari, S., Facchini, M. C., Kirchstetter, T. W., Maenhaut, W., and Artaxo, P.: Chemical Characterization of Fine Carbonaceous Aerosols during the Dry Season in the Amazon Basin: Black Carbon, Organic Carbon and Water-Soluble Organic Compounds, presented at: AGU Fall Meeting, San Francisco, CA, 15-19 December, 2000.

Mayol-Bracero, O. L., Guyon, P., Roberts, G. C., Andreae, M. O., Decesari, S., Facchini, M. C., Fuzzi, S., and Artaxo, P.: Water soluble organic compounds in biomass burning aerosols over Amazonia 2. Apportionment of the chemical composition and importance of the polyacidic fraction, J. Geophys. Res., 107, doi:10.14029/2001JD00522, 2002.

Mazurek, M. A., Cofer III, W. R., and Winstead, E. L.: Car- 
bonaceous aerosols from prescribed burning of a boreal forest, in: Global Biomass Burning: Atmospheric, Climatic, and Biospheric Implications, edited by: Levine, J. S., pp. 209-224, MIT Press, Cambridge, Mass, 1991.

Mazurek, M. A., Laterza, C., Newman, L., Daum, P., Cofer III, W. R., Levine, J. S., and Winstead, E. L.: Composition of carbonaceous smoke particles from prescribed burning of a Canadian boreal forest: organic aerosol characterization by gas chromatography, in: Global Biomass Burning and Global Change, edited by: Levine, J. S., pp. 840-847, MIT Press, Cambridge, Mass, 1996.

McDow, S. R. and Huntzicker, J. J.: Vapor adsorption artifact in the sampling of organic aerosol: Face velocity effects, Atmos. Environ., 24(A), 2563-2571, 1990.

McDow, S. R., Jang, M., Hong, Y., and Kamens, R. M.: An approach to studying the effect of organic composition on atmospheric aerosol photochemistry, J. Geophys. Res., 101, $19593-$ 19600, 1996.

McKenzie, L. M., Hao, W. M., Richards, G. N., and Ward, D. E.: Quantification of major components emitted from smoldering combustion of woods, Atmos. Environ., 28, 3285-3292, 1994.

McMurry, P. H. and Wilson, J. C.: Growth laws for the formation of secondary ambient aerosols: implications for chemical conversion mechanisms, Atmos. Environ., 16, 121-134, 1982.

Menaut, J. C., Lavenu, F., Loudjani, P., and Podaire, A.: Biomass burning in West African savannas, in: Global Biomass Burning, edited by: Levine, J. S., pp. 133-143, MIT Press, Cambridge MA, 1991.

Nakajima, T., Higurashi, A., Takeuchi, N., and Herman J. R.: Satellite and ground-based study of optical properties of 1997 Indonesian forest fire aerosols, Geophys. Res. Lett., 26, 2421-2424, 1999.

Nance, J. D., Hobbs, P. V., Radke, L. F., and Ward, D. E.: Airborne measurements of gases and particles from an Alaskan wildfire, J. Geophys. Res., 98, 14 873-14 882, 1993.

Novakov, T.: Soot in the atmosphere, in: Particulate carbon: Atmospheric life cycle, edited by: Wolf, G. T. and Klimish, R. L., pp. 19-41, Plenum, New York, 1982.

Novakov, T. and Corrigan, C. E.: Thermal characteristics of biomass smoke particles, Mikrochem. Acta, 119, 157-161, 1995.

Novakov, T. and Corrigan, C. E.: Cloud condensation nucleus activity of the organic component of biomass smoke particles, Geophys. Res. Lett., 23, 2141-2144, 1996a.

Novakov, T. and Corrigan, C. E.: Influence of sample composition on aerosol organic and black carbon determinations, in: Biomass Burning and Global Change, Vol. 1, edited by: Levine, J. S., pp. 531-539, 1996b.

Novakov, T., Hegg, D. A., and Hobbs, P. V.: Airborne measurements of carbonaceous aerosols on the East Coast of the United States, J. Geophys. Res., 102, 30 023-30 030, 1997.

Ohta, S. and Okita, T.: Measurements of particulate carbon in urban and maritime air in Japanese areas, Atmos. Environ, 18, 2439$2445,1984$.

Orr, C., Hurd, F. K., and Corbett, W. J.: Aerosol size and relative humidity, J. Colloid Sci., 13, 472-482, 1959

Page, S. E., Siegert, F., Rieley, J. O., Boehm, H. D. V., Jaya, A., and Limin, S.: The amount of carbon released from peat and forest fires in Indonesia during 1997, Nature, 420, 61-65, 2002.

Palmer, T. Y.: Large fire winds, gases and smoke, Atmos. Environ., 15, 2079-2090, 1981.
Patterson, E. M. and McMahon, C. K.: Absorption characteristics of forest fire particulate matter, Atmos. Environ., 18, 2541-2551, 1984.

Patterson, E. M., McMahon, C. K., and Ward, D. E.: Absorption properties and Graphitic carbon emission factors of forest fire smoke, Geophys. Res. Lett., 13, 129-132, 1986.

Penner, J. E., Dickinson, R., and O'Neil, C.: Effects of aerosol from biomass burning on the global radiation budget, Science, 256 , 1432-1434, 1992.

Penner, J. E. and Porch, W. M.: Coagulation in the smoke plumes after a nuclear war, Atmos. Environ., 21, 957-969, 1987.

Pereira, E. B., Setzer, A. W., Gerab, F., Artaxo, P. E., Pereira, M. C., and Monroe, G.: Airborne measurements of aerosols from biomass burning in Brazil related to the TRACE A experiment, J. Geophys. Res., 101, 23 983-23 992, 1996.

Posfai, M., Simonics, R., Li, J., Hobbs, P. V., and Buseck, P. R.: Individual aerosol particles from biomass burning in southern Africa: 1. Composition and size distributions of carbonaceous particles, J. Geophys. Res., 108(D13), 8483, doi:10.1029/2002JD002291, 2003.

Pruppacher, H. R. and Klett, J. D.: Microphysics of Clouds and Precipitation, pp. 172-178, Kluwer Academic Publishers, Boston, 1997.

Pyne, S.: Introduction to Wildland Fires: Fire Management in the United States, pp. 1-34, John Wiley, New York, 1984.

Radke, L. F., Hegg, D. A., Hobbs, P. V., Nance, J. D., Lyons, J. H., Laursen, K. K., Weiss, R. E., Riggan, P. J., and Ward, D. E.: Particulate and trace emissions from large biomass fires in North America, in: Global Biomass Burning: Atmospheric, Climatic, and Biospheric Implications, edited by: Levine, J. S., pp. 209 224, MIT Press, Cambridge, MA., 1991.

Radke, L. F., Hegg, D. A., Hobbs, P. V., and Penner, J. E.: Effects of aging on the smoke from a large forest fire, Atmos. Res., 38, 315-332, 1995.

Radke, L. F, Hegg, D. A., Lyons J. H., Brock, C. A., Hobbs, P. V., Weiss, R., Rassmussen, R.: Airborne measurements on smokes from biomass burning, in: Aerosols and Climate, edited by: Hobbs, P. V. and McCormick, M. P., pp. 411-422, Deepak Publishing, Hampton, VA, 1988.

Radke, L. F., Stith, J. L., Hegg, D. A., and Hobbs, P. V.: Airborne studies of particles and gases from forest fires, Air Pollution Control Assoc. J., 28, 30-34, 1978.

Radzi bin Abas, M., Simoneit, B. R. T., Elias, V., Cabral, J. A., and Cardoso, J. N.: Composition of higher molecular weight organic matter in smoke aerosol from biomass combustion in Amazonia, Chemosphere, 30, 995-1015, 1995.

Reid, J. S.: Emission, evolution, and radiative properties of particles from biomass burning in Brazil, Dissertation, University of Washington, University Microfilms, Ann Arbor MI, 1998.

Reid, J. S., Cahill, T. A., and Dunlap, M. R.: Geometric/aerodynamic size ratios of ash aggregates from burning Kuwaiti oil fields, Atmos. Environ., 28, 2227-2234, 1994.

Reid, J. S. and Hobbs, P. V.: Physical and optical properties of smoke from individual biomass fires in Brazil, J. Geophys. Res., 103, 32 013-32 031, 1998.

Reid, J. S., Hobbs, P. V., Liousse, C., Martins, J. V., Weiss, R. E., and Eck, T. F.: Comparisons of techniques for measuring shortwave absorption and black carbon content of aerosols from biomass burning in Brazil, J. Geophys. Res., 103, 32 031-32 040, 
1998a.

Reid, J. S., Hobbs, P. V., Ferek, R. J., Blake, D. R., Martins, J. V., Dunlap, M. R., and Liousse, C.: Physical, chemical and optical properties of regional hazes dominated by smoke in Brazil, J. Geophys. Res., 103, 32 059-32 080, 1998b.

Reid, J. S., Eck, T. F., Christopher, S., Dubovik, O., Koppmann, R., Eleuterio, D., Holben, B., Reid, E. A., and Zhang, J.: A Review of Biomass Burning Emissions Part III: Intensive Optical Properties of Biomass Burning Particles, Atmos. Chem. Phys. Discuss., 4, 5201-5260, 2004,

\section{SRef-ID: 1680-7375/acpd/2004-4-5201}

Reid, J. S., Eck, T. F., Christopher, S. A., Hobbs, P. V., and Holben, B. R.: Use of the Angstrom exponent to estimate the variability of optical and physical properties of aging smoke particles in Brazil, J. Geophys. Res., 104, 27 489-27 489, 1999a.

Reid, J. S., Hobbs, P. V., Rangno, A. L., and Hegg, D. A.: Relationships between cloud droplet effective radius, liquid water content, and droplet concentration for warm clouds in Brazil embedded in biomass smoke, J. Geophys. Res., 104, 6145-6153, 1999b.

Reiner, T., Sprung, D., Jost, C., Gabriel, R., Mayol-Bracero, O. L., Andreae, M. O., Campos, T. L., and Shetter, R. E.: Chemical characterization of pollution layers over the tropical Indian Ocean: Signatures of emissions from biomass and fossil fuel burning, J. Geophys. Res., 106, 28 497-28 510, 2001.

Roberts, G. C., Artaxo, P., Zhou, J., Sweitlicki, E., and Andreae, M. O.: Sensitivity of CCN spectra on chemical and physical properties of aerosol: A case study from the Amazon basin, J. Geophys. Res., 107, doi:10.1029/2001JD000583, 2002.

Rogers, C. M. and Bowman, K. P.: Transport of smoke from the Central American fires of 1998, J. Geophys. Res., 106, $28357-$ 28368, 2001.

Rogers, C. F., Hidson, J. G., Zeilinska, B., Tanner, R. L., Hallett, J., and Watson, J. G.: Cloud condensation Nuclei from biomass burning, in: Global Biomass Burning: Atmospheric, Climatic, and Biospheric Implications, edited by: Levine, J. S., pp. 431440, MIT Press, Cambridge, MA, 1991.

Rosenfeld, D.: TRMM observes first direct evidence of smoke from forest fires inhibiting rainfall, Geophys. Res Lett., 26, 31053108, 1999.

Ruellan, S., Cachier, H., Gaudichet, A., Masclet, P., and Lacaux, J.P.: Airborne aerosols over central Africa during the Experiment for Regional Sources and Sinks of Oxidants (EXPRESSO), J. Geophys. Res., 104, 30 673-30 690, 1999.

Sandberg, D. V., Pickford, S. G., and Darley, E. F.: Emissions from slash burnings and the influence of flame retardant chemicals, J. Air Poll. Control Assn., 25, 278-281, 1975.

Satsumabayashi, H., Kurita, H., Yokouchi, Y., and Ueda, H.: Particulate Di-carboxilic acids under long range transport in Central Japan, Atmos. Environ. Part A., 24, 1443-1450, 1990.

Schmid, H., Laskus, L., Abraham, H. J., et al.: Results of the "Carbon Conference" international aerosol carbon round robin test stage 1, Atmos. Environ., 35, 2111-2121, 2001.

Seiler, W. and Crutzen, P. J.: Estimates of gross and net fluxes of carbon between the biosphere and the atmosphere from biomass burning, Climatic Change, 2, 207-247, 1980.

Seinfeld, J. H. and Pandis, S. N.: Atmospheric Chemistry and Physics, John Wiley and Sons, New York, 1998.

Shah, J. J. and Rau, J. A.: Carbonaceous species methods compar- ison study: inter-laboratory round robin interpretation of results, Final Report from G2E Inc. to California Air Resources Board (G2E-0024), 77 pp, 1991.

Shea, R. W., Shea, W. B., Kauffman, J. B., Ward, D. E., Haskins, C. I., and Scholes, M. C.: Fuel biomass and combustion factors associated with fires in savanna ecosystems of South Africa and Zambia, J. Geophys. Res., 101, 23 551-23 568, 1996.

Silva, P. J., Liu, D.-Y., Noble, C. A., and Prather, K. A.: Size and chemical characterization of individual particles resulting from biomass burning of local Southern California species, Environ. Sci. Technol., 33, 3068-2375, 1999.

Simoneit B. R. T.: Biomass burning - A review of organic tracers for smoke from incomplete combustion, Appl. Geochem., 17, 129-162, 2002.

Simoneit, B. R. T., Radzi bin Abas, M., Cass, G. R., Rogge, W. F., Mazurek, M. A., Standley, L. J., and Hildermann, L. M.: Natural organic compounds as tracers for biomass combustion in aerosols, in: Global Biomass Burning: Atmospheric, Climatic, and Biospheric Implications, edited by: Levine, J. S., pp. 509517, MIT Press, Cambridge, MA, 1996.

Sinha, P., Hobbs, P. V., Yokelson, R. J., Bertschi, I. T., Blake, D. R., Simpson, I. J., Gao, S., Kirchstetter, T. W., and Novakov, T.: Emissions of trace gases and particles from savanna fires in southern Africa, J. Geophys. Res., 108(D13), 8487, doi:10.1029/2002JD002325, 2003.

Stith, J. L., Radke, L. F., and Hobbs, P. V.: Particulate emissions and the production of ozone and nitrogen oxides from the burning of forest slash, Atmos. Environ., 15, 73-82, 1981.

Stocks, B. J., van Wilgen, B. W., Trollope, W. S. W., McRae, D. J., Mason, J. A., Weirich, F., and Potgieter, A. L. F.: Fuels and fire behavior dynamics on large-scale savanna fires in Kruger National Park, South Africa, J. Geophys. Res., 101, 23 541-23 550, 1996.

Susott, R. A., Olbu, G. J. , Baker, S. P., Ward, D. E., Kauffman, J. B., and Shea, R. W.: Carbon, hydrogen, nitrogen, and thermogravimetric analysis of tropical ecosystem biomass, in: Global Biomass Burning: Atmospheric, Climatic, and Biospheric Implications, edited by: Levine, J. S., pp. 249-259, MIT Press, Cambridge, MA, 1996.

Susott, R. A., Ward, D. E., Babbitt, R. E., and Latham, D. J.: The measurement of trace emissions and combustion characteristics for a mass fire, in: Biomass Burning and Global Change, edited by: Levine, J. S., pp. 245-257, MIT Press, Cambridge MA, 1991.

Tanner, R. L., Gaffney, J. S., and Phillips, M. F.: Determination of organic and elemental carbon in atmospheric aerosol samples by thermal evolution, Anal. Chem., 54, 1627-1630, 1982.

Tillman, D. A.: Review of mechanisms associated with wood combustion, Wood Sci., 13, 177-184, 1981.

Trentmann, J., Andreae, M. O., and Graf, H.-F.: Chemical processes in a young biomass-burning plume, J. Geophys. Res., 108, 47054715, 2003.

Trollope, W. S. W., Trollope, L. A., Potgieter, A. L. F., and Zambatis, N.: SAFARI-92 characterization of biomass and fire behaviour in the small experimental burns in the Kruger National Park, J. Geophys. Res., 101, 23 531-23 539, 1996.

Turco, R. P. and Fangqun, Y.: Particle size in an expanding plume undergoing simultaneous coagulation and condensation, J. Geophys. Res., 104, 19227-19241, 1999. 
Turco, R. P., Toon, O. B., Ackerman, T. P., Pollack, J. B., and Sagan, C.: Nuclear winter, global consequences of multiple nuclear explosions, Science, 222, 1283-1292, 1983.

Turco, R. P. and Yu, F.: Aerosol invariance in expanding coagulation plumes, Geophys. Res. Lett., 24, 1223-1226, 1997.

Turn, S. Q., Jenkins, B. M., Chow, J. C., Pritchett, L. C., Cambell, D., Cahill, T., and Whalen, S. A.: Elemental characterization of particulate matter emitted from biomass burning: Wind tunnel derived source profiles for herbaceous and wood fuels, J. Geophys. Res., 102, 3683-3699, 1997.

Turns, S. R.: An Introduction to Combustion, Concepts and Applications, pp. 291-297, McGraw Hill, New York, 1996.

Turpin, B. J. and Lin, H.-J.: Species contributions to PM2.5 mass concentrations: Revisiting common assumptions for estimating organic mass, Aero. Sci. Tech., 35, 602-610, 2001.

Turpin, B. J., Saxena, P., and Andrews, E.: Measuring and simulating particulate organics in the atmosphere: problems and prospects, Atmos. Environ, 34, 2983-3013, 2000.

Wandinger, U., Muller, D., Bockmann, C., Althausen, D., Matthias, V., Bosenberg, J., Weiss, V., Fieberg, M., Wendisch, M., Stohl, A., and Ansmann, A.: Optical and microphysical characterization of biomass burning and industrial pollution aerosols from multi-wavelength lidar and aircraft measurements, J. Geophys. Res., 107, doi:10.1029/2000JD000202, 2002.

Ward, D. E.: Particulate matter production from cylindrical laminar diffusion flames, in: Proceedings Fall Meeting of the Western States Section of the Combustion Institute, Los Angeles, CA 18 pp, 1980.

Ward, D. E.: Factors influencing the emissions of gases and particulate matter from biomass burning, in: Fire in the Tropical Biota, edited by: Goldammer, J. G., pp. 418-436, SpringerVerlag, 1990.

Ward, D. E., Sandberg, D. V., Ottmar, R. D., Anderson, J. A., Hofner, G. G., and Fitzsimmons, C. K.: Measurements of smokes from two prescribed fires in the Pacific Northwest, Seventy-Fifth Annual Meeting of the Air Pollution Control Association, 1982.

Ward, D. E. and Hardy, C. C.: Smoke emissions from wildland fires, Environ. Intern., 17, 117-134, 1991.

Ward, D. E., Hardy, C. C., and Sandberg, D. V.: Emission factors for particles from prescribed fires by region in the United States, in: PM10: Implementation of Standards, edited by: Mathai, C. V. and Stonefield, C. H., 372-386, Proceedings of APCA/EPA Int. Spec. Conf., February, San Francisco, CA, 1988.
Ward, D. E. and Hao, W. M.: Air toxic emissions from burning of biomass globally-preliminary estimates, in Proceedings: Air \& Waste Management Assoc. 85th Annual Meeting \& Exhibition, 1992.

Ward, D. E., Hao, W. M., Susott, R. A., Babbitt, R. E., Shea, R. W. Kauffman, J. B., and Justice, C. O.: Effect of fuel composition on combustion efficiency and emission factors for African savanna ecosystems, J. Geophys. Res., 101, 23 569-23 576, 1996.

Ward, D. E., Setzer, A. W., Kaufman, Y. J., and Rasmussen, R. A.: Characteristics of smoke emissions from biomass fires of the Amazon region-BASE-A experiment, in; Biomass Burning and Global Change, edited by: Levine, J. S., pp. 394-402, MIT Press, Cambridge MA, 1991.

Ward, D. E., Susott, R. A., Kauffman, J. B., et al.: Smoke and fire characteristics for cerrado and deforestation burns in Brazil: Base-B Experiment, J. Geophys. Res., 97, 14 601-14 619, 1992.

Warner, J. and Twomey, S.: The production of cloud nuclei by cane fires and the effect on cloud drop concentrations, J. Atmos. Sci. 24, 704-713, 1967.

Wong, J. and Li, Z.: Retrieval of optical depth for heavy smoke aerosol plumes: uncertainties and sensitivities to the optical properties, J. Atmos. Sci., 59, 250-261, 2002.

Woods, D. C., Chuan, R. L., Coffer III, W. R., and Levine, J. S.: Aerosol characterization in smoke plumes from a wetlands fire, in: Global Biomass Burning: Atmospheric, Climactic and Biospheric Implications, edited by: Levine, J. S., pp. 240-244, MIT Press, New York, 1991.

World Climate Program (WCP): A Preliminary Cloudless Standard Atmosphere for Radiation Computations, WCP-112, WMO/TDNo. 24, 24 March, 1986.

Yamasoe, M. A., Artaxo, P., Miguel, A. H., and Allen, A. G.: Chemical composition of aerosol particles from direct emissions of vegetation fires in the Amazon Basin: water-soluble species and trace elements, Atmos. Environ., 34, 1641-1653, 2000.

Yu, S. C.: Role of organic acids (formic, acetic, pyruvic and oxalic) in the formation of cloud condensation nuclei $(\mathrm{CCN})$ : a review, Atmos. Res., 53, 185-217, 2000. 